\title{
Inflammatory priming enhances mesenchymal stromal cell secretome potential as a clinical product for regenerative medicine approaches through secreted factors and EV-miRNAs: the example of joint disease
}

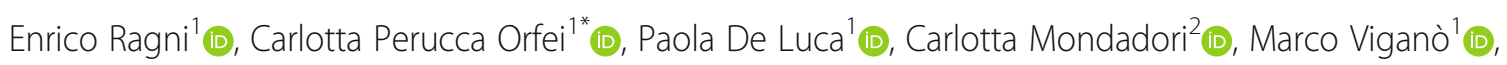
Alessandra Colombini ${ }^{1}$ (i) and Laura de Girolamo ${ }^{1}$ (D)

\begin{abstract}
Background: Mesenchymal stromal cell (MSC)-enriched products showed positive clinical outcomes in regenerative medicine, where tissue restoration and inflammation control are needed. GMP-expanded MSCs displayed an even higher potential due to exclusive secretion of therapeutic factors, both free and conveyed within extracellular vesicles (EVs), collectively termed secretome. Moreover, priming with biochemical cues may influence the portfolio and biological activities of MSC-derived factors. For these reasons, the use of naive or primed secretome gained attention as a cell-free therapeutic option. Albeit, at present, a homogenous and comprehensive secretome fingerprint is still missing. Therefore, the aim of this work was to deeply characterize adipose-derived MSC (ASC)secreted factors and EV-miRNAs, and their modulation after IFNY preconditioning. The crucial influence of the target pathology or cell type was also scored in osteoarthritis to evaluate disease-driven potency.

Methods: ASCs were isolated from four donors and cultured with and without IFNY. Two-hundred secreted factors were assayed by ELISA. ASC-EVs were isolated by ultracentrifugation and validated by flow cytometry, transmission electron microscopy, and nanoparticle tracking analysis. miRNome was deciphered by high-throughput screening. Bioinformatics was used to predict the modulatory effect of secreted molecules on pathologic cartilage and synovial macrophages based on public datasets. Models of inflammation for both macrophages and chondrocytes were used to test by flow cytometry the secretome anti-inflammatory potency.

(Continued on next page)
\end{abstract}

\footnotetext{
*Correspondence: carlotta.perucca@grupposandonato.it

${ }^{1}$ IRCCS Istituto Ortopedico Galeazzi, Laboratorio di Biotecnologie Applicate all'Ortopedia, Via R. Galeazzi 4, Milan 20161, Italy

Full list of author information is available at the end of the article
}

(c) The Author(s). 2020 Open Access This article is licensed under a Creative Commons Attribution 4.0 International License, which permits use, sharing, adaptation, distribution and reproduction in any medium or format, as long as you give appropriate credit to the original author(s) and the source, provide a link to the Creative Commons licence, and indicate if changes were made. The images or other third party material in this article are included in the article's Creative Commons. licence, unless indicated otherwise in a credit line to the material. If material is not included in the article's Creative Commons licence and your intended use is not permitted by statutory regulation or exceeds the permitted use, you will need to obtain permission directly from the copyright holder. To view a copy of this licence, visit http://creativecommons.org/licenses/by/4.0/ The Creative Commons Public Domain Dedication waiver (http://creativecommons.org/publicdomain/zero/1.0/) applies to the data made available in this article, unless otherwise stated in a credit line to the data. 
(Continued from previous page)

Results: Data showed that more than 60 cytokines/chemokines could be identified at varying levels of intensity in all samples. The vast majority of factors are involved in extracellular matrix remodeling, and chemotaxis or motility of inflammatory cells. IFNy is able to further increase the capacity of the secretome to stimulate cell migration signals. Moreover, more than 240 miRNAs were found in ASC-EVs. Sixty miRNAs accounted for > 95\% of the genetic message that resulted to be chondro-protective and M2 macrophage polarizing. Inflammation tipped the balance towards a more pronounced tissue regenerative and anti-inflammatory phenotype. In silico data were confirmed on inflamed macrophages and chondrocytes, with secretome being able to increase M2 phenotype marker CD163 and reduce the chondrocyte inflammation marker VCAM1, respectively. IFNy priming further enhanced secretome antiinflammatory potency.

Conclusions: Given the portfolio of soluble factors and EV-miRNAs, ASC secretome showed a marked capacity to stimulate cell motility and modulate inflammatory and degenerative processes. Preconditioning is able to increase this ability, suggesting inflammatory priming as an effective strategy to obtain a more potent clinical product which use should always be driven by the molecular mark of the target pathology.

Keywords: Mesenchymal stromal cells, Adipose tissue, Secreted factors, miRNAs, Secretome, Osteoarthritis, Inflammation, Cartilage, Macrophage

\section{Background}

At present, few mesenchymal stromal cell (MSC)-based products have gained marketing approval by the regulatory authorities [1] and mainly rely on MSCs derived from bone marrow (BMMSCs), adipose tissue (ASCs), or umbilical cord (WJMSCs), reflecting the main sources of MSCs tested for clinical trials being currently bone marrow, adipose, and umbilical cord tissues [2]. Clinical indications are largely related to musculoskeletal (bone regeneration and osteoarthritis (OA)) and inflammatory (Chron's and GvHD) diseases. This is in agreement with positive clinical outcomes of MSC-enriched products, as bone marrow concentrate or microfragmented fat tissue, in one-step regenerative medicine approaches where both tissue restoration and inflammation control are needed, as in joint pathologies [3]. Under these premises, due to higher concentration of the active biological components, GMP-expanded MSCs are postulated to have an even higher and more focused potential in both autologous and allogeneic therapies. Nevertheless, available products are all sourced and manufactured through distinct processes, rendering direct potency comparison and disease-driven selection challenging. Moreover, sheer complexity of living mammalian cells makes MSC characterization/specification at both functional and molecular levels extraordinarily difficult, delaying a fast and wider use of these cells in regenerative medicine applications.

These premises prompted the identification of a MSCbased product able to retain originating cell potency but easier to be characterized and standardized. In the last years, it has been proposed that therapeutic effects of MSCs may be ascribed to secreted cytokines and growth factors $[4,5]$, as well as different types of extracellular vesicles (EVs) [6], altogether defining the secretome. EVs shuttle both 3'UTR mRNA fragments competing with recipient miRNAs or proteins [7], together with mRNAs and miRNAs with multiple functions as immunomodulation and tissue restoration $[8,9]$. Thus, secretome as a whole or its separate components gained attention as an innovative cell-free medicinal product for those pathologies involving both immune system and tissue homeostasis unbalance $[10,11]$.

With the view of MSC secretome clinical translation, to date, few phase I/II clinical trials were performed [12-16]. Together with safety, secretome showed reduction of inflammation and long-lasting clinical improvements $[13,16]$. For these reasons, attention increased, and at present (December 2019), 4 trials are registered for MSC secretome or purified EVs in a wide range of pathologies: refractory macular holes (NCT03437759), type 1 diabetes mellitus (NCT02138331), chronic skin ulcer (NCT04134676), and acute ischemic stroke (NCT03384433). Positive results will stimulate further studies to test safety and efficacy in other diseases where MSCs have been studied in completed phase I/II/III clinical trials, as for the treatment of musculoskeletal diseases where positive outcomes laid the foundations for the marketing of MSC-based products [17].

MSCs and secretome potential may be further modulated by extrinsic factors, such as tissue source or pro- $/$ anti-inflammatory environment $[18,19]$, able to polarize MSCs towards either a pro-inflammatory or an immunosuppressive phenotype [20], with pro-inflammatory factors such as TNF $\alpha$, IL-1 $\beta$, or IFN $\gamma$ activating the latter that is also involved in tissue regeneration [11]. In particular, IFN $\gamma$ results in the differential expression of 210 cellular proteins [21], including immunomodulatory molecules 
[22]. Consistently, in an equine model of osteoarthritis, IFN $\gamma$-primed MSCs reduced synovial effusion, improved cartilage gross appearance, and delayed progression of proteoglycan loss [23]. Similarly, in experimental colitis, IFN $\gamma$-preconditioned MSCs showed a significant reduction of inflammatory responses [24]. In general, the majority of tested priming approaches, through modulation of both secreted factors and EV-embedded miRNAs [25], were able to improve MSC therapeutic efficacy [26] and laid the groundwork for a higher clinical efficacy of the secretome.

Nevertheless, many limitations still delay the clinical translation, such as high costs, variable effects depending on tissue source and donor variability, and lack of clear therapeutic application based on the portfolio of secreted molecules. Further, to facilitate approval of therapeutic applications, xenogenic components such as FBS or inflammatory molecules used for priming should be avoided at least during the EV production and harvest phase. Notably, the majority of reports assessing both the secreted factors and their modulation after priming do not consider this aspect, with exogenous molecules and particles possibly diluting, altering, or blocking some effects of MSC secretome. Therefore, the aims of this study are to characterize both secreted factors and EVembedded miRNAs and to evaluate their modulation after IFNY preconditioning, in the serum-free secretome of ASCs. Bioinformatics analysis of potentially regulated pathways and a list of markers for the development of future release assays are provided, in order to allow a more profound understanding of MSC secretome for the treatment of different conditions such as $\mathrm{OA}$ as an example of pathology-focused potency evaluation.

\section{Methods}

\section{Adipose-derived mesenchymal stromal cell isolation and} expansion

Adipose waste material from four female donors (median 54 years old, min 45, max 61) undergoing liposuction was digested with $0.075 \% \mathrm{w} / \mathrm{v}$ type I collagenase $\left(30 \mathrm{~min}\right.$ at $37^{\circ} \mathrm{C}$ ) (Worthington Biochemical Co, Lakewood, NJ, USA). Digested samples were filtered through a cell strainer and centrifuged $(1000 \times g, 5 \mathrm{~min})$. Pelleted cells were seeded at $5 \times 10^{3}$ cells $/ \mathrm{cm}^{2}$ in DMEM $+10 \%$ FBS (GE Healthcare, Piscataway, NJ, USA) and penicillin-streptomycin (Life Technology, Carlsbad, CA, USA). Cells were cultured at $37^{\circ} \mathrm{C}, 5 \% \mathrm{CO}_{2}$, and $95 \%$ humidity. Cells were cultured until $90 \%$ confluence with medium change each 3 days. At $90 \%$ density, cells were detached and either frozen or seeded at 4000 cells $/ \mathrm{cm}^{2}$. Cells were used for experiments at passage 5 at $90 \%$ confluence, 1 day after the last medium change. ASCs were primed with $10 \mathrm{ng} / \mathrm{ml} \mathrm{IFN \gamma}$ for $48 \mathrm{~h}$ (iASCs). Afterwards, culture flasks were washed five times with PBS and medium without serum added. After $48 \mathrm{~h}$, conditioned medium (secretome) was collected and further processed.

\section{ASC characterization}

Flow cytometry was used to score positive or negative MSC or hemato/endothelial markers (CD44-PE Vio770 clone REA690, CD73-PE clone REA804, and CD90-FITC clone REA897 or CD34-FITC clone AC136, CD31-PerCp Vio700 clone REA730, and CD45-PE Vio770 clone REA747; Miltenyi Biotec, Bergisch Gladbach, Germany) with a CytoFLEX flow cytometer (Beckman Coulter, Fullerton, CA, USA) collecting a minimum of 10,000 events.

\section{qRT-PCR analysis}

ASCs in growth medium or growth medium supplemented with $10 \mathrm{ng} / \mathrm{ml} \mathrm{IFN \gamma}$ for $48 \mathrm{~h}$ were washed twice with PBS and directly lysed in TRIzol reagent (Sigma-Aldrich, St. Louis, MO, USA). RNA was extracted following standard procedures [27]. First-strand cDNAs were synthesized with iScript cDNA synthesis kit (Bio-Rad Laboratories, CA, USA) [28]. Primers for CXCL9/10, CCL5/8, COX2, HGF, HIF1A, IDO1, IL-6, IL-8, and FGF2 were designed using the NCBI Primer Designing Tool (http://www.ncbi.nlm.nih.gov/tools/primer-blast/). $T B P$ was used as a reference for gene quantification. Primer sequences will be provided upon request. Quantifications were performed using "PowerUp SYBR Green Master Mix" (Applied Biosystems, Warrington, UK) and Comparative Ct Method in a StepOne Plus PCR Real Time Instrument (Applied Biosystems) [29]. Unprimed ASCs were used as control.

\section{Extracellular vesicle isolation and characterization}

Conditioned medium was collected and subjected to differential centrifugation steps to remove broken cells and debris. Briefly, the medium was centrifuged at $4{ }^{\circ} \mathrm{C}$ for $15 \mathrm{~min}$ at $1000 \times g$ and $2000 \times g$ and twice at $4000 \times g$. Five milliliters of last supernatant was 1:2 diluted with PBS and centrifuged at $100,000 \times g$ for $9 \mathrm{~h}$ at $4{ }^{\circ} \mathrm{C}$ in a $70 \mathrm{Ti}$ rotor (Beckman Coulter, Fullerton, CA, USA), and EV pellets were processed as follows:

i) Flow cytometry: before ultracentrifugation, conditioned media were supplemented with $10 \mu \mathrm{M}$ CFSE (Sigma-Aldrich) and incubated for $1 \mathrm{~h}$ at $37^{\circ} \mathrm{C}$. After ultracentrifugation, as previously described, pellets were suspended in $100 \mu \mathrm{l}$ PBS per $10 \mathrm{ml}$ of processed medium. Labeled EVs were 1:10,000 diluted in PBS and $100 \mu$ l stained with anti CD81-APC clone 5A6 and anti CD63-APC clone H5C6 (Biolegend, San Diego, CA, USA) for $30 \mathrm{~min}$ at $4{ }^{\circ} \mathrm{C}$ in the dark. Antibodies were used 
individually. Collection was performed with a CytoFLEX flow cytometer collecting events for $30 \mathrm{~s}$ at $10 \mu \mathrm{l} / \mathrm{min}$ flow rate. Flow cytometer was set with a reference bead mix (Biocytex, Marseille, France) composed of a FITC fluorescent mixture of spheres $(100 \mathrm{~nm}, 300 \mathrm{~nm}, 500 \mathrm{~nm}$, and $900 \mathrm{~nm})$. Gains were $\mathrm{FSC}=106, \mathrm{SSC}=61, \mathrm{FITC}=272, \mathrm{PE}=116$, and PC7 $=371$. FITC threshold was set at 500 to include 100-nm beads and some smaller debris in the FITC channel.

ii) Transmission electron microscopy: after EV pellet suspension in PBS, $5 \mu$ l was absorbed on formvar carbon-coated grids for $10 \mathrm{~min}$. Drops were blotted with filter paper. Two percent uranyl acetate aqueous suspension was used to negative stain for 10 $\mathrm{min}$, and excess was removed by filter paper. Afterwards, the grid was dried at room temperature. Samples were examined with a TALOS L120C transmission electron microscope (Thermo Fisher Scientific, Waltham, MA, USA) at $120 \mathrm{kV}$.

iii) Nanoparticle tracking analysis (NTA): EVs in conditioned medium (1:3 diluted in PBS) or purified EVs in PBS (1:100 diluted) were visualized by the NanoSight LM10-HS system (NanoSight Ltd., Amesbury, UK). Three recordings of $30 \mathrm{~s}$ were performed for each sample. Collected data were analyzed by the NTA software, providing concentration measurements and high-resolution particle size distribution profiles.

\section{Screening of EV-embedded miRNA expression}

EV pellets were dissolved in TRIzol reagent and RNA extracted with the miRNeasy Kit and RNeasy CleanUp Kit (Qiagen, Hilden, Germany), following the manufacturer's instruction. During extraction, $6 \mathrm{pg}$ of a nonhuman synthetic miRNA (Arabidopsis thaliana athmiR-159a) was added to each sample as a spike-in to monitor the technical variability during the isolation and following reactions for eventual equalization of panels $\mathrm{A}$ and $B$ of the OpenArray ${ }^{\circ}$ platform (Life Technologies). cDNAs were prepared by standard reverse transcription (RT) and preamplification procedures with A and B independent kits, followed by real-time RT-PCR analysis with the QuantStudio ${ }^{\mathrm{Tm}} 12 \mathrm{~K}$ Flex OpenArray ${ }^{\circ}$ Platform (QS12KFlex) as previously described [30]. The Gene Expression Suite Software (Life Technologies) was used to process miRNA expression data from the A and B miRNA panels, together covering 754 well-characterized human miRNA sequences from the Sanger miRBase v21. The global mean was selected as the normalization method due to the high correlation between samples [31]. $C_{R T}>28$ were considered as unamplified. Normalized miRNA expression was determined using the relative quantification $2-\Delta C_{R T}$. Values are shown as normalized $\mathrm{Ct}$ and ratios calculated separately for each sample as primed vs unprimed and then mean values \pm SD calculated.

\section{ELISA assays}

Concentrations of 200 soluble inflammatory and growth factors, chemokines, receptors, and cytokines in conditioned cell culture medium were determined by Quantibody Human Cytokine Array 4000 Kit (https://www. raybiotech.com/quantibody-human-cytokine-array-4000/ ) according to the manufacturers' instructions (RayBiotech, Norcross, GA, USA). 1:2 dilutions of culture supernatants were made to have absorbance readings within the standard curve values. Only factors that were detected above single assay threshold in all samples, either resting or primed, were selected for the analysis. The amount of each factor was calculated multiplying the concentration in $\mathrm{pg} / \mathrm{ml}$ per the volume of culture medium and eventually divided per million cell to obtain a $\mathrm{pg} / 10^{6}$ cell value. Values are shown as pg or ng per million cells and ratios calculated separately for each sample as primed vs unprimed and then mean values \pm SD calculated.

\section{Construction and analysis of protein-protein interaction (PPI) networks}

The online tool STRING (http://www.string-db.org) to construct interactome maps of ELISA identified proteins (STRING database v11 data accessed: March 2020). The indicated network properties include organism, Homo sapiens; meaning of network edges, evidence; active interaction sources, experiments and databases; and minimum required interaction scores, medium confidence (0.400).

\section{Pathway analysis Identification of functional annotations}

Protein Proteins identified in ASCs or iASC secretome were subjected to functional enrichment analysis to provide insight into the functional associations of these protein subsets. This analysis was performed using GO: TermFinder for enrichment of biological process (BP) Gene Ontology (GO) terms (https://go.princeton.edu/ cgi-bin/GOTermFinder). Statistical significance was calculated setting $p$ value cutoff for significant shared GO terms at 0.01 and using Bonferroni and FDR corrections [32]. When no enriched GO terms were found, a list of proteins was submitted to the PANTHER web interface (http://www.pantherdb.org/) to identify proteins encompassing the same functional classifications, following default settings [33]. Selected classification was PantherGO Slim Biological Process. 
miRNA The predicted miRNA targets were annotated into functional BP using DIANA-miRPath V. 3 (http:// snf-515788.vm.okeanos.grnet.gr/), using microT-CDS to score for predicted miRNA-mRNA interaction (threshold 0.8), $p$ value threshold of 0.05 for the GO category and FDR correction [34]. Further analysis was performed using the microRNA Target Filter tool in Ingenuity Pathway Analysis (IPA; Ingenuity Systems, www.ingenuity.com). Filters were confidence "experimentally observed" and disease "skeletal and muscular disorders" or "inflammatory response" to score focused pathways (see the "Results" section).

\section{Principal component analysis}

Principal component analysis (PCA) plots were generated scoring factors or miRNAs with ClustVis package (https://biit.cs.ut.ee/clustvis/), after row centering [35]. pg factors per million cells or miRNA $C_{R T}$ after normalization values were used.

\section{Secretome validation on inflamed macrophages and chondrocytes by flow cytometry}

Human primary monocytes were isolated from three buffy coats of healthy donors that were obtained from the local blood bank, by Ficoll (GE Healthcare, Little Chalfont, UK) density gradient separation, followed by positive magnetic selection using CD14 microbeads (MACS, Miltenyi) [36]. After isolation, CD14+ monocytes were plated in 12-well plates at a density of 300 , 000 monocytes $/ \mathrm{cm}^{2}$ and cultured for 5 days in complete medium supplemented with $10 \%$ heat-inactivated FBS and $1 \%$ penicillin-streptomycin-glutamine. Macrophage colony-stimulating factor (M-CSF, Peprotech Inc., Rocky Hill, NJ, USA) was added to the culture medium at 20 $\mathrm{ng} / \mathrm{ml}$ to differentiate monocytes towards macrophages [37]. Following differentiation into macrophages for 5 days, cells were then cultured for $24 \mathrm{~h}$ in complete medium (supplemented with 10\% ultracentrifuged FBS to avoid serum EVs) in 4 different conditions. Experiments were conducted either in the absence or in the presence of pro-inflammatory cytokines, IFNY at $100 \mathrm{ng} /$ $\mathrm{ml}$ and TNF $\alpha$ at $100 \mathrm{ng} / \mathrm{ml}$, always including M-CSF at $20 \mathrm{ng} / \mathrm{ml}$ (human, all from Peprotech) [37]. Specifically, macrophages cultured only with M-CSF represented the unstimulated macrophages (M0), whereas macrophages cultured with IFN $\gamma$ and TNF $\alpha$ represented the polarized macrophages (M1). These two conditions were used as control groups. Other two conditions were prepared to test the anti-inflammatory potential of secretome on M1 macrophages in the presence of an inflammatory stimulus. To this aim, M1 macrophages cultured with M-CSF, IFN $\gamma$, and TNF $\alpha$ were treated with pooled secretome obtained by resting ASC or by ASC primed with IFN $\gamma$. All the procedures were conducted using 10\% ultracentrifuged FBS as a medium supplement. After 24 $h$, cells were washed twice with PBS and detached by incubating them with cell dissociation buffer (Thermo Fisher, Frankfurt, Germany) for $10 \mathrm{~min}$. Cells were then centrifuged at $400 \times g$ for 7 min, suspended in FACS buffer and counted. Fifty thousand cells were then stained with monoclonal antibodies to analyze through flow cytometry technique the expression of M1 proinflammatory (CD86) and M2 anti-inflammatory (CD163) macrophage markers. Briefly, cells were stained at $4{ }^{\circ} \mathrm{C}$ for $30 \mathrm{~min}$ in the dark with anti-human $\mathrm{CD} 14$ FITC (clone TUK4, Miltenyi), for macrophage gating; anti-human CD86-PE (Clone FM95, Miltenyi), for M1 phenoptype; and anti-human CD163-PE-Vio770 (Clone REA812, Miltenyi), for M2 phenotype. Unstained cells were used as negative control for fluorescence. After wash in FACS buffer, at least 30,000 events were acquired with a Cytoflex flow cytometer (Beckman Coulter).

Chondrocytes were obtained from three OA (Kellgren Lawrence III or IV) patients undergoing total hip arthroplasty, as in [38]. Briefly, the cartilage was harvested with a scalpel from non-weight bearing superficial areas of femoral head/neck, and chondrocytes were isolated by enzymatic digestion $\left(37^{\circ} \mathrm{C}, 22 \mathrm{~h}\right)$ with $0.15 \%$ w/v type II collagenase (Worthington Biochemical, Lakewood, NJ, USA), then cultured in DMEM + 10\% FBS. When $90 \%$ confluence was reached, cells were detached and seeded at $4000 \mathrm{cells} / \mathrm{cm}^{2}$. At passage 3, chondrocytes were seeded and, when at $90 \%$ confluence, either control medium or control medium $+25 \mathrm{pg} / \mathrm{ml} \mathrm{IL}-1 \beta$ added. After 3 days, four conditions were run: control (DMEM $+10 \%$ FBS), $25 \mathrm{pg} / \mathrm{ml} \mathrm{IL}-1 \beta$ in control medium, IL- $1 \beta$ in resting ASC secretome (+10\% FBS), or IL- $1 \beta$ in primed ASC secretome $(+10 \% \mathrm{FBS})$. Ultracentrifuged FBS was used to avoid serum EVs interference. After 4 days, cells were washed, detached, and counted. Fifty thousand cells were stained in the dark at $4{ }^{\circ} \mathrm{C}$ for 30 min with human anti-VCAM1 (clone HA58, Miltenyi). Unstained cells were used as negative control for fluorescence. After FACS buffer wash, at least 30,000 events were acquired with a Cytoflex flow cyotometer (Beckman Coulter).

\section{Statistical analyses}

For secretome analysis, in each experiment, four independent cultures were included. Only proteins or miRNAs present and quantified in all unprimed, primed, or both conditions were considered as positively identified. Statistical analysis was performed using the GraphPad Prism software (GraphPad, San Diego, CA, USA). Kolmogorov-Smirnov normality test was used to test normal data distribution. Grubbs' test was used to identify outliers. A one sample $t$ test was used to compare the mean ratios (IFNY vs untreated, factors, or miRNAs) 
with a hypothetical mean value set as 1 as per absence of modulation. The level of significance was set at $p$ value value $<0.05$. Data was presented as mean \pm SD. For macrophages and chondrocytes analysis, three independent populations were studied. Kolmogorov-Smirnov and Grubb's tests were used. One sample $t$ test was used for ratios to compare means vs reference values set as 1 , and $t$ test of two means was used for other comparisons, with significance set at $p$ value $<0.05$. Data was presented as mean $\pm \mathrm{SD}$.

\section{Results}

\section{Effect of the stimulation with IFNy on ASCs}

ASCs were tested using specific surface markers by flow cytometry: ASCs (Fig. 1a) were completely negative for the hemato-endothelial markers (CD31, CD34, and CD45; Fig. $1 \mathrm{~b}$ ) and $>95 \%$ positive for the mesenchymal stromal cells markers CD44, CD73, and CD90 (Fig. 1c). To determine whether inflammatory stimuli may influence surface marker expression, cells were tested in the presence of IFN $\gamma$ at a concentration of $10 \mathrm{ng} / \mathrm{ml}$ for 48 h. No alterations were detected (data not shown). Cell viability was also not affected, with $96 \% \pm 0.5$ viable cells before and $95 \% \pm 1$ after IFN $\gamma$ stimulation.

We next examined the effect of IFN $\gamma$ on the RNA expression of several reporters known to be related with the transcriptional response to different inflammatory stimuli (Fig. 1d). IFNY response trend was shared across all ASCs under study suggesting a conserved pattern of modulation, with significant (fold $<$ or $>2, p$ value $<$ 0.05) increase for IDO1, CXCL9/10, CCL5/8, and COX2 and decrease for $I L 8$ (Fig. 1d). Notably, with the only exception of CCL5 (fold of $1.12 \pm 1.25$ ), CXCL9/10, CCL8, and IL8 confirmed the significant modulation also when their presence was monitored in the conditioned medium after $48 \mathrm{~h}$ removal of the inflammatory stimulus (see next paragraphs).

\section{ASC-secreted factors}

A selection of 200 inflammatory and growth factors, chemokines, receptors, and cytokines was scored on ASC-conditioned medium. Fifty-seven molecules were
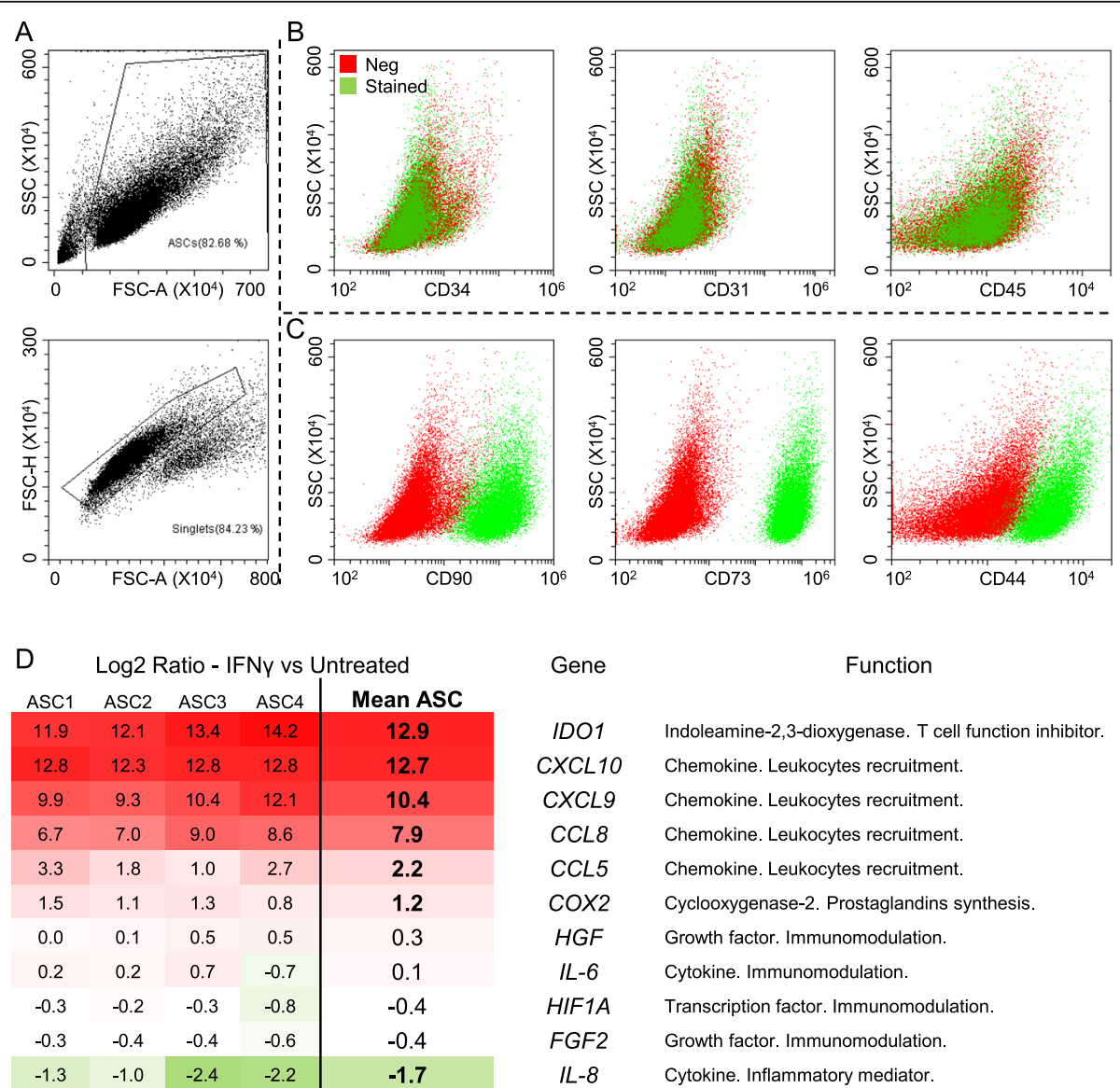

Fig. 1 ASC characterization and inflammatory modulation. a, c Representative dot plots of hemato-endothelial (CD31-34-45) and MSC (CD44-7390) markers in ASCs. One representative cell isolate is shown. $\mathbf{d}$ IFNy effects on targets reported to be modulated by different inflammatory stimuli. Log2 ratios of iASCs vs ASCs are shown 
found above the ELISA detection threshold at varying levels of intensity in all ASC samples (Additional file 1: Table 1 and Additional file 2). A pattern of similarity more than divergence between samples was observed since a correlation analysis showed a mean $R$ value of $0.92 \pm 0.06$. Consequently, an average intensity value was calculated for each factor in order to provide a guide to its level. In $48 \mathrm{~h}$, per million cells, 4 factors were secreted with an average amount superior to $100 \mathrm{ng}$, namely FST (531 \pm 220$)$, TIMP2 $(200 \pm 21)$, IGFBP4 $(144 \pm 40)$, and SERPINE1 $(101 \pm 4)$. The average amount of 10 factors was between 10 and $100 \mathrm{ng}$ : IGFBP6 ( $85 \pm 3)$, IL6ST (46 \pm 16$)$, TIMP1 $(31 \pm 3)$, IL6 $(22 \pm 28)$, CTSS (19 \pm 9$)$, PLG (17 \pm 2$)$, TNFRSF1A $(15 \pm 6)$, CCL2 $(13 \pm 3)$, DKK1 $(10 \pm 2)$, and IGFBP3 $(10 \pm 4)$. The average amount of 18 factors was between 1 and $10 \mathrm{ng}$ and others 26 below 1 ng. A functional protein association network analysis (Fig. 2a) of the 57 proteins, regardless their expression amount and based on known interactions given by experimental and database sources, identified a specific cluster (Fig. 2b), composed in its core by CXCL1/5/8/ $12 / 16$ and CCL4/5/13/27, all involved in chemotaxis and immune response, and, more distant, CTSS/TIMP2, related to extracellular matrix remodeling.

To give a more detailed overview of the secretome potential that goes beyond the association networks, a Gene Ontology (GO) analysis was performed against the background population (200 assayed factors), being aware that a selected protein list was scored. When assessing the 14 most abundant proteins ( $>10 \mathrm{ng}$ per million cells), two functional categories resulted significantly enriched: extracellular matrix disassembly (GO: 0022617; $p$ value 5.5e-04; PLG, IL6, CTSS, and TIMP1/ 2) and cellular component disassembly (GO:0022411; 6.7e-04; PLG, IL6, CTSS, TIMP1/2, DKK1). These results, in agreement with the association network, suggest a potential in the regulation of processes involved in matrix remodeling. Analyzing the molecules with intermediate expression (1-10 ng), no enriched functional categories were found. To get more insights, biological processes (BP) were scored using the PANTHER GOSlim Biological Processes tool. The BP encompassing the highest number of proteins, as previously emerged for the association network cluster, were connected with chemotaxis/motility and immune response. Specifically, granulocyte (GO:0071621; CCL4/5 and CXCL1/5/8) and leukocyte (GO:0030595; CCL4/5, CXCL1/5/8, and VEGFA) chemotaxis, cell migration (GO:0016477) and cell motility (GO:0048870), both defined by CCL4/5, CXCL1/5/8, VEGFA, AXL, and FLT1. For the inflammatory response (GO:0006954), again, CCL4/5 and CXCL1/5/8 defined this category. These results suggest a potential effect of ASC-secreted factors on host immune cells. Finally, the functional categories related to the less abundant $(<1 \mathrm{ng})$ ones were analyzed. No enriched GO terms were obtained. Mining the BP containing the highest number of members, immune system categories arose: response to stimulus (GO:0050896; CCL3/13/27, CD14, IL1B, SIGLEC5, TGFB1, and TNFSF14), with some of the factors (CCL3/13, CXCL16, IL1B, and TYRO3) also defining cell migration (GO: 0016477) and motility (GO:0048870). Notably, CCL3/13, CXCL16, and IL1B were part of leukocyte chemotaxis (GO:0030595) and migration (GO:0050900). Again, immune cells resulted a target of ASC secreted factors, even when expressed at low levels.

\section{IFNY influence on ASC-secreted molecules}

After IFN $\gamma$ preconditioning $(48 \mathrm{~h}, 10 \mathrm{ng} / \mathrm{ml}), 58$ factors were scored (Additional file 2: Table 2), with a high correlation between inflamed samples (mean $R$ of $0.97 \pm$ 0.02). PCA analysis demonstrated that in a context of overall similarity considering all 8 samples ( \pm inflammation, mean $R$ of $0.95 \pm 0.06$ ) (Fig. 3a), IFNy priming allowed for a sharp discrimination of samples (Fig. 3b). Inflammation leads to loss of few factors (Fig. 3c): IGFBP3, IL1B, KITLG, TNFSF14, and CXCL12. On contrary, CXCL10 (14.9 $\pm 6.6 \mathrm{ng})$ and CXCL9 $(19.9 \pm 10.4$ ng) appeared at high levels and VCAM1 $(1.4 \pm 0.7 \mathrm{ng})$ and CCL8 $(3.7 \pm 1.9 \mathrm{ng})$ at moderate amounts, whereas IFNG and CCL7 were barely detectable. Regarding modulated factors (Fig. 3c), in the untreated samples $>10 \mathrm{ng}$ group, only CTSS significantly ( $p$ value $<0.05$ ) increased (3.71-fold). ICAM1 and IL2RB increased in all samples, 4.22- and 4.64-fold, respectively, reaching high levels (> $10 \mathrm{ng}$ ) although without statistical significance ( $p$ value between 0.1 and 0.05 ). Conversely, few factors reduced their expression: ANG, CXCL5, PLAUR, CXCL8, and CXCL1. For the low expressed factors in unprimed ASCs (<1 ng), CXCL16 (5.28-fold; $2.0 \pm 0.2 \mathrm{ng}$ ) and CCL13 (183.81-fold; $1.1 \pm 0.8 \mathrm{ng}$ ) increased their expression, although the last one have a $p$ value of 0.0808 . Other low abundant factors significantly reduced their expression, remaining barely detected molecules. The functional protein association network analysis resulted very similar to the one previously obtained (Fig. 2c), with the identification of a tight cluster (Fig. 2d) composed of CXCL1/5/8/9/10/16 and CCL4/5/13/27, and more distant, CTSS/TIMP2, again emphasizing IFN $\gamma$-primed secretome influence on chemotaxis/immune response and matrix remodeling.

A more detailed Gene Ontology enrichment analysis on the newly synthesized molecules did not find overor under-represented terms. Notably, PANTHER was able to identify BP encompassing the majority of factors, as response to stimulus (GO:0050896), granulocyte (GO:0071621) and leukocyte (GO:0050900) chemotaxis, cell migration (GO:0016477) and motility 


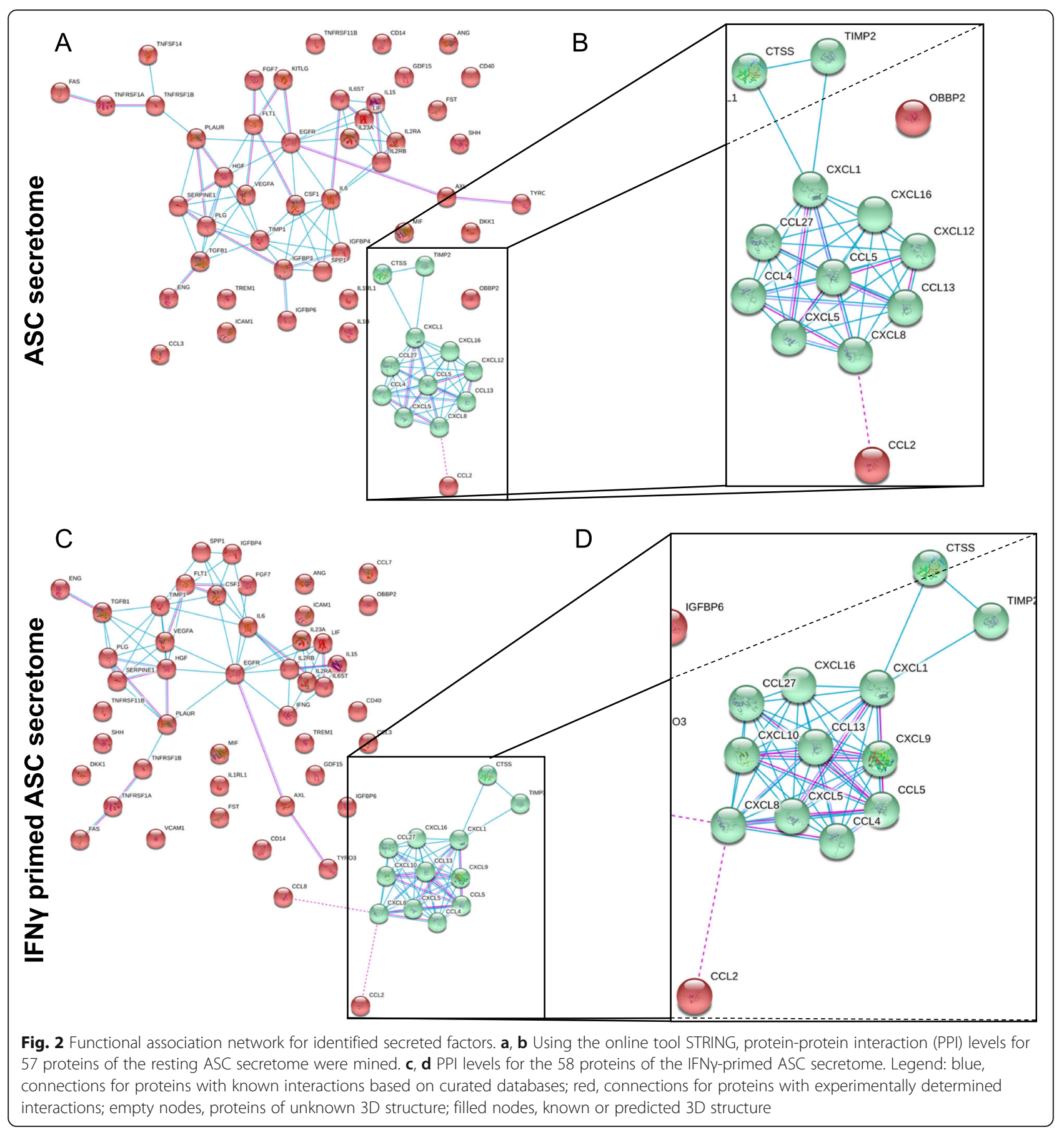

(GO:0048870), and inflammatory response (GO: 0006954), all defined by (CCL7/8 and CXCL9/10). Therefore, staying in the rut of previously observed secretome, IFN $\gamma$ may further increase modulation on the immune system cells. Regarding the factors that are lost with inflammation, for both GO enrichment analysis and BP scoring, no significant terms were found.
Characterization of ASC-derived extracellular vesicles ASCs release around 13,500 extracellular vesicles (from now on termed EVs) per cell in $48 \mathrm{~h}$. IFN $\gamma$ preconditioning significantly $(p$ value $<0.05)$ increases vesicle (iEV) production of a $1.7 \pm 0.3$ ratio, reaching 22,200 particles/ cell (Fig. 4a). Isolated EVs were analyzed by transmission electron microscopy and nanoparticle tracking analysis (NTA). EVs exhibited the characteristic cup-shape 

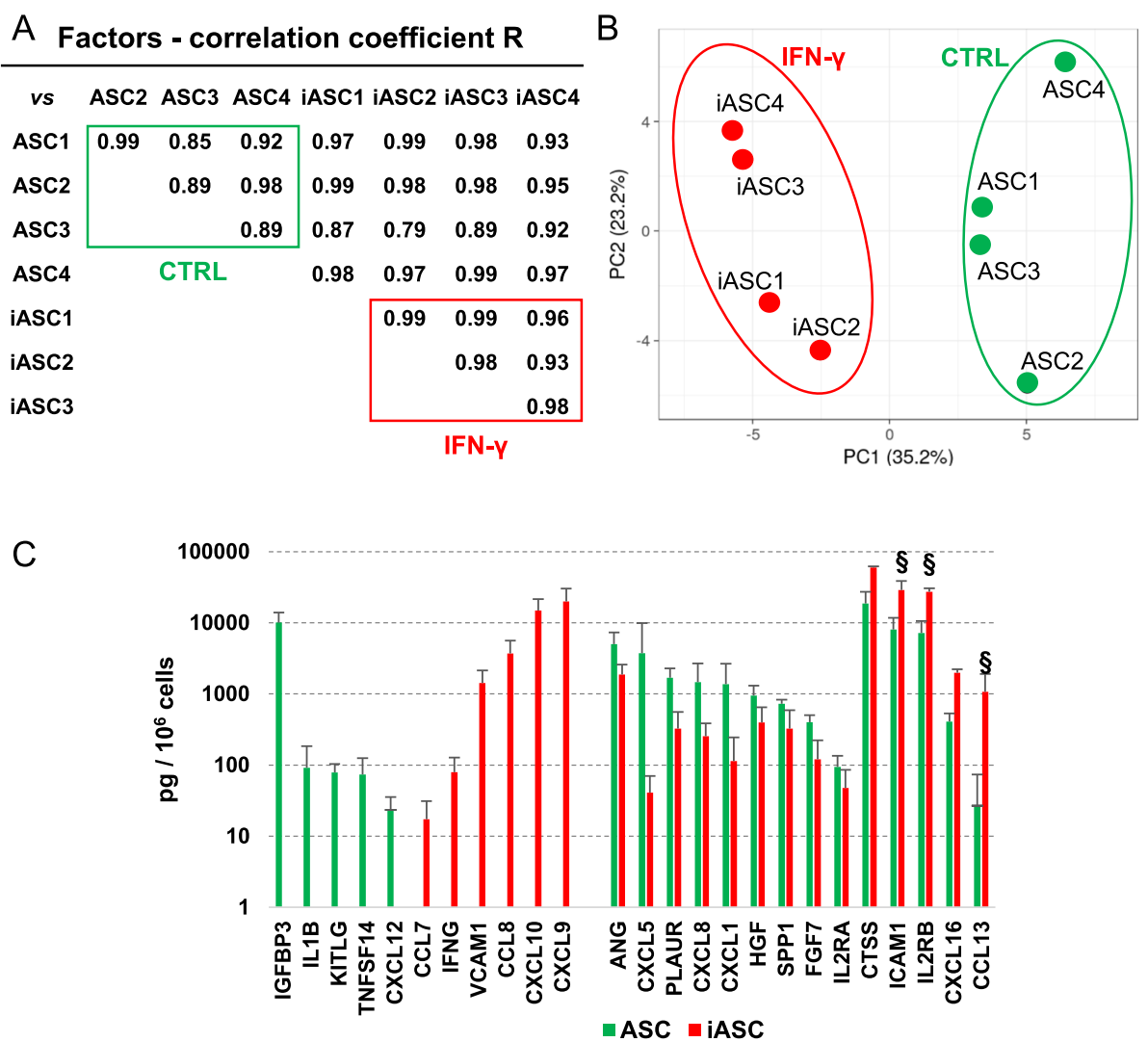

Fig. 3 Cytokine and growth factor secretion in ASCS and inflammatory modulation. a Correlation of the 57 factors identified by ELISA, in ASCS and iASCs. Absolute values are shown in Additional file 2: Table 2. b Principal component analysis demonstrating IFNy effect on global factor expression. PCA was generated after row centering. c Newly secreted, depleted, or modulated factors after IFNy. All modulated factors have a statistical significance with a $p$ value $<0.05$ (see Additional file 2: Table 2), with the exception of ICAM1, ILR2RB, and CCL13 ( $\$ p$ value $<0.1$ )

morphology (Fig. 4b) and were within the reported size range $(50-400 \mathrm{~nm}$ in diameter), with enrichment in the small ones $(<150 \mathrm{~nm})$ (Fig. 4c). After inflammation, iEVs resulted larger (193 \pm 28 vs $162 \pm 9 \mathrm{~nm}$ ), although without reaching statistical significance ( $p$ value of 0.0796$)$ (Fig. 4d). After calibration of the flow cytometer to detect particles in the nanometer range (100 to $900 \mathrm{~nm}$, Fig. 4e), both EVs and iEVs demonstrated to express vesicle markers CD63 $(53.1 \% \pm 0.3$ for EVs and $51.1 \% \pm$ 0.8 for $\mathrm{iEVs})$ and CD81 $(61.5 \% \pm 1.5$ for EVs and $60.4 \% \pm 1.1$ for iEVs) at comparable levels (Fig. 4f), consistent with previously reported characteristics of extracellular vesicles.

\section{EV-associated miRNAs}

A total of 242 miRNAs for EVs and 222 for iEVs were detected (Additional file 3: Table 3). Inter-correlation analysis showed high conservation $(R$ of $0.99 \pm 0.01)$ for EVs and iEVs groups (Fig. 5a). After IFNY stimulation, both correlation ( $R$ of $0.74 \pm 0.01$ ) and PCA showed distinct clusters (Fig. 5a, b), due to 10 miRNAs appearing and 30 disappearing and 7 candidates significantly ( $p$ value $<0.05$, fold $>2$ ) overexpressed (miR-146b-5p/146b-3p/155-5p/ $210-3 \mathrm{p} / 29 \mathrm{~b} / 3 \mathrm{p} / 455-5 \mathrm{p} / 886 / 3 \mathrm{p})$ and 9 reduced (fold $<2$ ) (miR-145-5p/149-5p/199a-5p/221-3p/27a-3p/27b-3p/3455p/503-5p/671-3p), after inflammation.

Next, we scored embedded miRNAs significance. Recent findings suggested that even for most abundant EV-conveyed miRNAs, there is around 1.3 molecules per MSC vesicle [39], and 100 EVs would be needed to transfer one copy of an abundant miRNA [40]. Due to these premises, only highly expressed molecules, such as those laying in the first quartile of expression (61 and 56 miRNAs for EVs and iEVs, respectively, covering 96.8\% and $95.9 \%$ of the genetic message), were considered (Fig. 5c). Few miRNas were not included in both lists, although significant difference in the expression or loss/ gain was a rare event. miR-320a-3p and miR-132-3p were not expressed at all in iEVs, whereas miR-27b-3p and miR-149-5p resulted significantly (ratio $<0.5, p$ value $<0.05$ ) downregulated (ratio of 0.49 and 0.14 , respectively) under inflammation. Conversely, iEVS-enriched miR-382-5p and let-7e-5p were not amplified at all in unprimed EVs, with miR-146b-5p/29b-3p/886-3p less 

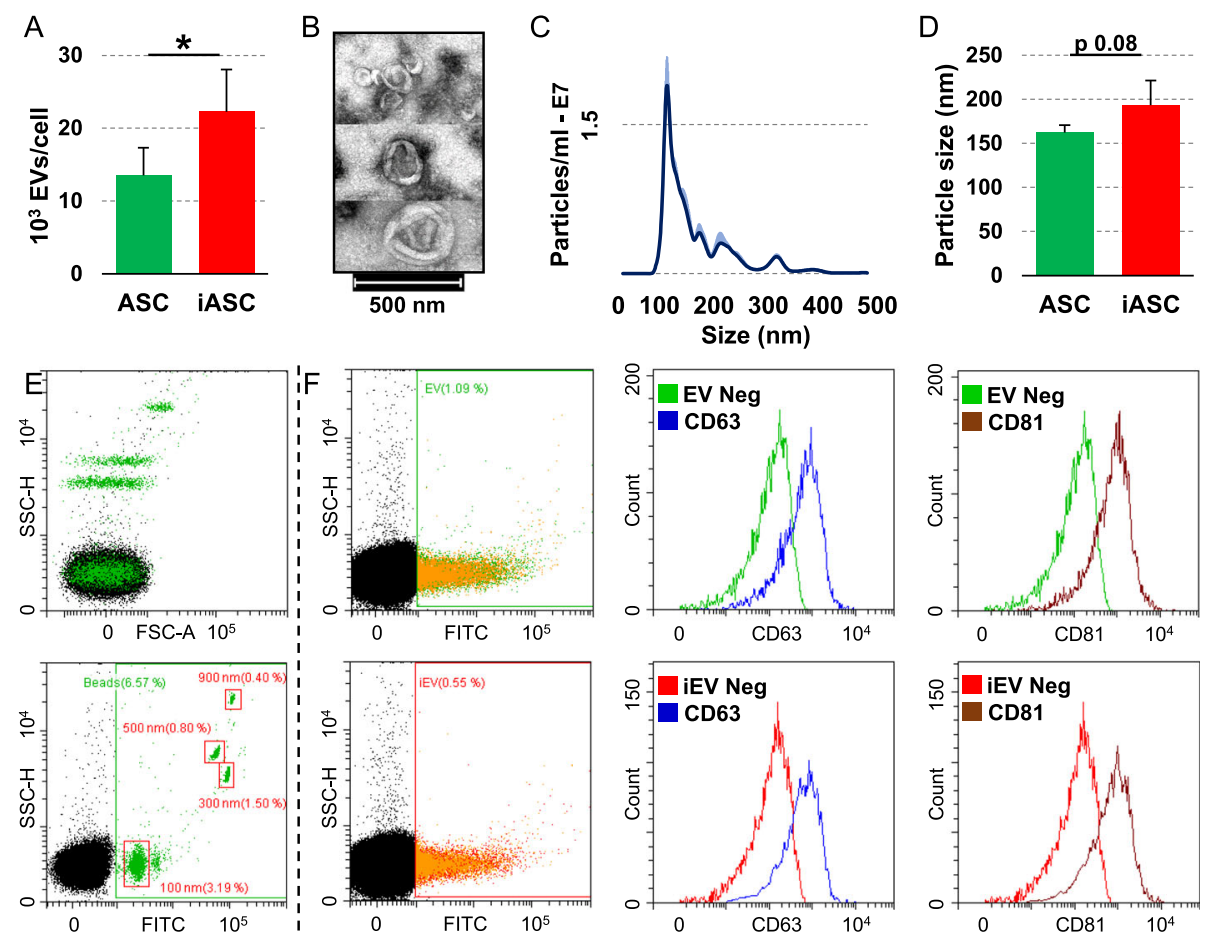

Fig. 4 ASC-EV characterization. a Number of EVs secreted per cell in $48 \mathrm{~h}$. b Transmission electron micrographs of ASC-derived vesicles showing particles with characteristic cup-shaped morphology. c Size distribution of nanoparticles by NanoSight particle tracking analysis. d Mean particle size analysis from NTA data. e Setting up the EV-dedicated flow cytometer. The resolution of the reference bead mix indicates the flow cytometer performance in light scattering at default settings. The top cytogram shows the side scatter height (SSC-H) versus forward scatter area (FSC-A). The bottom cytogram depicts the SSC-H versus 535/35 (green fluorescence triggering) channel. Four fluorescent populations (100, 300, 500, and $900 \mathrm{~nm}$ ) were resolved from the instrument noise. $\mathbf{f}$ Flow cytometry analysis of ASC-EVs and iASC-EVs. EVs were stained with CFSE to allow identification and gating of vesicles in the FITC channel. After gating, CFSE+ EVs showed positive extracellular vesicle defining molecules CD63 and CD81. Representative cytograms are presented

expressed $(0.08,0.29$, and 0.40$)$ without inflammation. Due to these small differences, miRNAs from both quartiles were considered together, defining a group of 67 molecules (Fig. 5c). In this list, 5 miRNAs resulted downregulated (miR-221-3p/145-5p/27a-3p/27b-3p/149$5 \mathrm{p})$ and 4 upregulated (miR-210-5p/146b-5p/29b-3p/ 886-3p) by IFN $\gamma$, with miR-320a-3p and miR-132-3p EVs specific and miR-382-5p and let-7e-5p iEVs distinctive.

\section{EV-embedded miRNAs target analysis and IFNy influence}

Sixty-three miRNAs obtained from combined first quartiles candidates, excluding those unique to EVs (miR320a-3p/132-3p) or iEVs (has-miR-382-5p/let-7e-5p), were analyzed with mirPath to identify potential BP targets based on in silico predicted miRNA-mRNA interactions (Additional file 4: Table 4). Out of 24 enriched ( $p$ value $<\mathrm{e}-3) \mathrm{BP}$, the top five GO terms were cellular nitrogen compounds metabolic process (GO:0034641; 1.8e -157; 2484 genes), biosynthetic process (GO:0009058; $6.9 \mathrm{e}-109 ; 2088$ genes), cellular protein modification process (GO:0006464; 3.1e-95; 1304 genes), small molecule metabolic process (GO:0044281; 1.6e-58; 1187 genes), and symbiosis (GO:0044403; 7.3e-43; 299 genes). Although with lower significance, three terms were related with those identified for secreted factors: immune system process (GO:0002376; 5.4e-12; 717 genes), cell motility (GO:0048870; 3.8e-10; 275 genes), and extracellular matrix organization (GO:0030198; 2.3e-4; 162 genes). miR-320a-3p/132-3p and miR-382-5p/let-7e-5p resulted able to potentially regulate $1006 / 703$ and 28 / 1692 genes, respectively, allowing the definition of a relevant number of significant BP (18 and 24, respectively). This lead to $16 \mathrm{GO}$ terms shared with the previous analysis, with 13 in the top of the ranking for both EVs and iEVs. Notably, immune system process was again predicted to be significantly regulated with a higher number of genes for iEVs (156 vs 137), whereas extracellular matrix organization was identified only for iEVs list, with low $p$ value (2.3e-3; 40 genes). Nevertheless, even with a reduced number of miRNAs, as 2 in our case, the most significantly enriched GO terms are similar for both category and heterogeneity, making almost impossible to predict either subtle or even general differences in potency without the definition of a specific target disease/tissue or transcript list. 


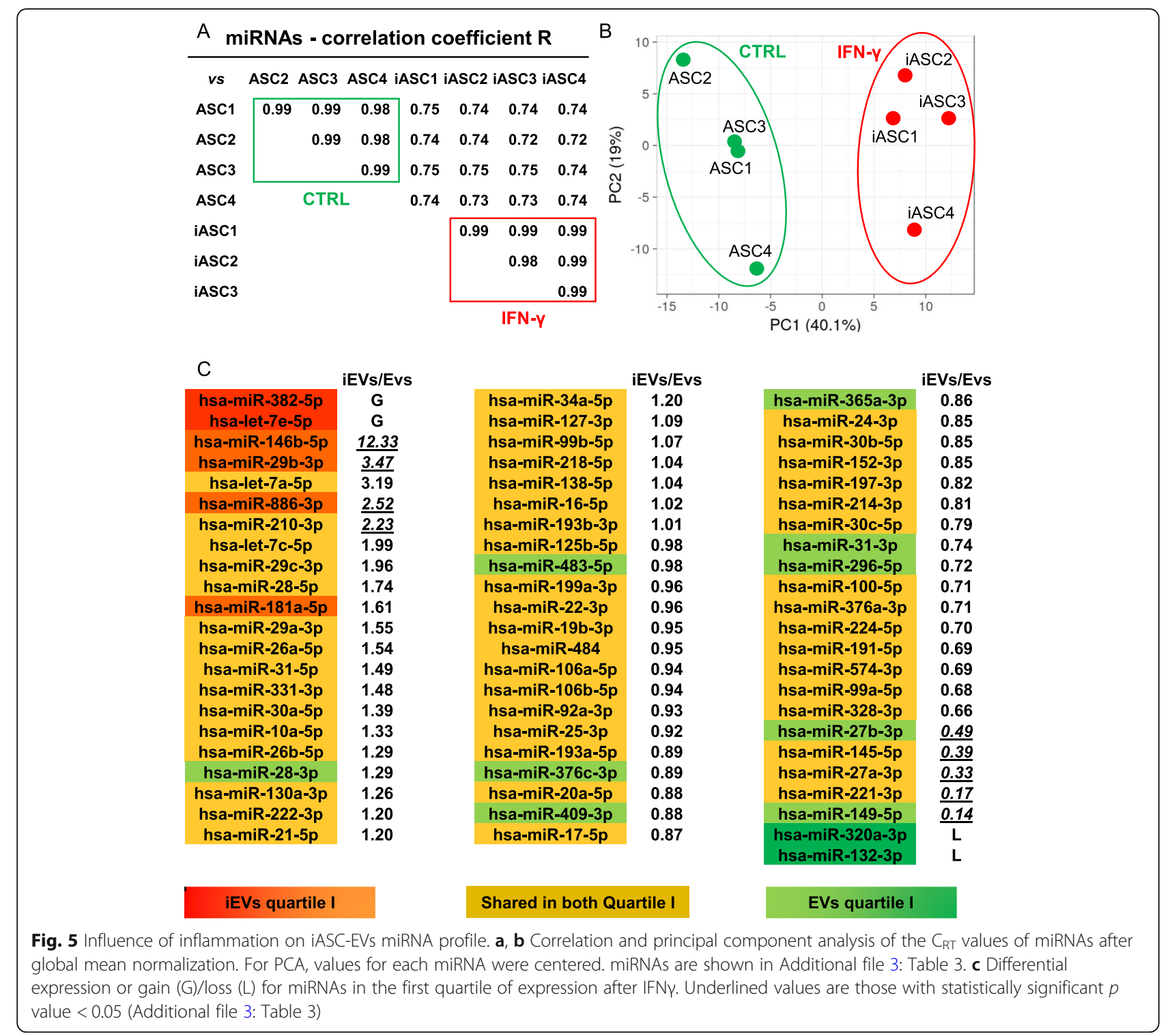

Due to the above findings, we focused our attention on miRNA-mRNA regulation in OA setting, being matrix-enriched cartilage and immune cells among the main pathological players and the majority of authorized MSC-based products related to musculoskeletal indications. Ingenuity Pathway Analysis on experimentally verified miRNA-mRNA interactions identified $42 \mathrm{miR}$ NAs related to "skeletal and musculoskeletal disorders." Of these miRNAs, 31 were directly or indirectly involved in the "osteoarthritis pathway" (Additional file 5: Table 5). A more refined search for miRNAs linked to "inhibition of matrix metalloproteases" showed subgroups defined by 8 miRNAs. With respect to "inflammatory response," 41 miRNAs directly regulate mRNAs covering different pathways: "inflammasome" was represented by 4 miRNAs, "chemokine signaling" 12 miRNAs, "altered
T and B cell signaling" 9 miRNAs, and finally, "role of macrophages, fibroblasts, and endothelial cells" $31 \mathrm{miR}$ NAs (Additional file 5: Table 5). Therefore, again, extracellular matrix and immune system resulted preferential targets.

To get further insights on the specifically regulated biological processes, a more refined and literature-based analysis was performed on miRNAs reported to directly regulate specific tissues or cell types [41, 42]. Ten and 7 miRNAs were associated with cartilage protection or degenerescence, respectively (Table 1 ). For protective molecules, IFN $\gamma$ reduced the expression of miR-149, involved in inflammation, and increased the amount of miR-210, also involved in inflammation and apoptotic processes. Concerning destructive functions, IFN $\gamma$ reduces miR-145 that is involved in chondrocyte 
Table $1 \mathrm{EV}$-miRNAs in the first quartile of expression that are involved in cartilage-protective/degenerative mechanisms

\begin{tabular}{|c|c|c|c|c|c|c|c|}
\hline & $\begin{array}{l}\text { \% weight EVs/ } \\
\text { iEVs }\end{array}$ & $\begin{array}{l}\text { Down } \\
\text { IFNy }\end{array}$ & $\begin{array}{l}\text { Up } \\
\text { IFNy }\end{array}$ & $\begin{array}{l}\text { Only } \\
\text { EVs }\end{array}$ & $\begin{array}{l}\text { Only } \\
\text { iEVs }\end{array}$ & Target genes & Functions \\
\hline \multicolumn{8}{|c|}{ Cartilage protective } \\
\hline hsa-miR-21-5p & $5.13 / 6.73$ & & & & & GAS5, GDF5 & Autophagy \\
\hline $\begin{array}{l}\text { hsa-miR-222- } \\
3 p\end{array}$ & $5.74 / 7.61$ & & & & & MMP13, HDAC4 & Cartilage degradation \\
\hline $\begin{array}{l}\text { hsa-miR-138- } \\
5 p\end{array}$ & $0.19 / 0.21$ & & & & & $S P 1, H I F-2 A$ & Chondrocyte differentiation \\
\hline hsa-miR-24-3p & $19.63 / 18.47$ & & & & & P16INK4A & $\begin{array}{l}\text { Chondrocyte differentiation and } \\
\text { apoptosis }\end{array}$ \\
\hline $\begin{array}{l}\text { hsa-miR-210- } \\
3 p\end{array}$ & $0.23 / 0.56$ & & $x$ & & & $D R 6, N F-K B$ & Inflammation, chondrocyte apoptosis \\
\hline $\begin{array}{l}\text { hsa-miR-26a- } \\
5 p\end{array}$ & $0.64 / 1.06$ & & & & & $\begin{array}{l}\text { NF-KB, CD200, COL10A1, COL9A1, } \\
\text { CTGF }\end{array}$ & $\begin{array}{l}\text { Inflammation, modulate ECM } \\
\text { homeostasis }\end{array}$ \\
\hline $\begin{array}{l}\text { hsa-miR-130a- } \\
3 p\end{array}$ & $0.57 / 0.78$ & & & & & TNF-A & Inflammation \\
\hline $\begin{array}{l}\text { hsa-miR-149- } \\
5 p\end{array}$ & $0.13 / 0.02$ & $x$ & & & & TNFA, IL-1, IL-6 & Inflammation \\
\hline $\begin{array}{l}\text { hsa-miR-199a- } \\
3 p\end{array}$ & $0.92 / 0.97$ & & & & & $\operatorname{cox}-2$ & Inflammation \\
\hline $\begin{array}{l}\text { hsa-miR-320- } \\
3 p\end{array}$ & $0.00 / 0.53$ & & & $x$ & & MMP13 & Matrix degradation \\
\hline \multicolumn{8}{|c|}{ Cartilage destructive } \\
\hline hsa-miR-21-5p & $5.13 / 6.73$ & & & & & GDF5 & $\begin{array}{l}\text { Chondrocyte differentiation and } \\
\text { homeostasis }\end{array}$ \\
\hline $\begin{array}{l}\text { hsa-miR-145- } \\
5 p\end{array}$ & $1.84 / 0.79$ & $x$ & & & & SOX9, SMAD3 & $\begin{array}{l}\text { Chondrocyte differentiation and } \\
\text { homeostasis }\end{array}$ \\
\hline hsa-miR-16-5p & $0.40 / 0.44$ & & & & & SMAD3 & $\begin{array}{l}\text { Chondrocyte differentiation and } \\
\text { homeostasis }\end{array}$ \\
\hline $\begin{array}{l}\text { hsa-miR-193b- } \\
5 p\end{array}$ & $5.00 / 5.56$ & & & & & TGF-B2, TGF-BR3, SOX9, COL2 & $\begin{array}{l}\text { Chondrocyte differentiation and } \\
\text { homeostasis }\end{array}$ \\
\hline $\begin{array}{l}\text { hsa-miR-29b- } \\
3 p\end{array}$ & $0.07 / 0.27$ & & & & & $S M A D, N F-K B, W N T$ & $\begin{array}{l}\text { Chondrocyte differentiation and } \\
\text { homeostasis }\end{array}$ \\
\hline $\begin{array}{l}\text { hsa-miR-34a- } \\
5 p\end{array}$ & $0.70 / 0.93$ & & & & & COL2A1, INOS & Chondrocyte apoptosis \\
\hline $\begin{array}{l}\text { hsa-miR-483- } \\
5 p\end{array}$ & $0.12 / 0.11$ & & & & & BMP7, TGFB, IL-1B, MMP13 & Inflammation \\
\hline
\end{tabular}

differentiation. As a whole message, protective miRNAs represented the $34.71 \%$ of EVs genetic weight vs the $13.28 \%$ of the destructive ones, indicating a strong preponderance of the salvage functions. Further, preconditioning slightly increases the percentage of miRNAs in both categories $(36.41 \%$ vs $14.83 \%)$, maintaining the delta between protection and degeneration at similar levels. Regarding immune system, we investigated miRNA-regulating factors orchestrating the macrophage M1 (pro-inflammatory) to M2 (anti-inflammatory) switch and phenotype (Table 2), being the imbalance a crucial factor linked to severity level of knee osteoarthritis [43]. Seven M1-related miRNAs were found in ASC-EVs, with IFNY reducing the levels of M1promoting miR-27a-3p/miR-27b-3p and miR-145-5p and increasing miR-29b-3p. For M2 miRNAs, 5 candidates were identified in the vesicles, having miR146b-5p augmented after inflammatory priming. As a whole, in EVs M2-related miRNAs, weight accounted for $26.22 \%$ vs $4.49 \%$ for M1 molecules, indicating a clear preponderance for resolving mechanisms. IFN $\gamma$ was able to improve the trend, being M2 vs M1 delta increased (28.76\% vs $3.61 \%)$. Therefore, overall in the OA settings, EV-miRNAs may have protective roles on both cartilage and inflammatory macrophages, with preconditioning able to tip the trend towards an even higher protective phenotype.

\section{Validation of secretome effects and IFN $\gamma$ priming on inflamed macrophages}

In silico data suggested an anti-inflammatory capacity for both secreted factors and EV-embedded miRNAs. 
Table 2 EV-miRNAs in the first quartile of expression that are involved in macrophage M1 or M2 phenotype

\begin{tabular}{|c|c|c|c|c|c|c|c|c|c|}
\hline & $\%$ weight EVs/iEVs & Down IFNy & Up IFNy & Only EVs & Only iEVs & M1 promoting & M1 suppressing & M2 promoting & M2 suppressing \\
\hline \multicolumn{10}{|l|}{ M1 phenotype } \\
\hline miR-29b-3p & $0.07 / 0.27$ & & $x$ & & & $x$ & & & \\
\hline miR-145-5p & $1.84 / 0.79$ & $x$ & & & & $x$ & & & \\
\hline miR-27a-3p & $0.90 / 0.33$ & $x$ & & & & $x$ & & & $x$ \\
\hline miR-27b-3p & $0.32 / 0.18$ & $x$ & & & & $x$ & & & $x$ \\
\hline miR-130a-3p & $0.57 / 0.78$ & & & & & $x$ & & & $x$ \\
\hline miR-26a-5p & $0.64 / 1.06$ & & & & & & & & $x$ \\
\hline miR-26b-5p & $0.15 / 0.20$ & & & & & & & & $X$ \\
\hline \multicolumn{10}{|l|}{ M2 phenotype } \\
\hline miR-24-3p & $19.63 / 18.47$ & & & & & & $x$ & $x$ & \\
\hline miR-146b-5p & $0.04 / 0.51$ & & $x$ & & & & $x$ & $x$ & \\
\hline miR-181a-5p & $0.11 / 0.18$ & & & & & & $x$ & $x$ & \\
\hline miR-34a-5p & $0.70 / 0.93$ & & & & & & & $x$ & \\
\hline miR-222-3p & $5.74 / 7.61$ & & & & & & & $x$ & \\
\hline
\end{tabular}

Moreover, IFN $\gamma$ priming appeared to potentiate the secretome healing properties. To validate bioinformatics, human macrophages were treated for $24 \mathrm{~h}$ with IFNy and TNF $\alpha$, and both M1 marker CD86 and M2 marker CD163 levels were tested by flow cytometry. As expected, inflammation resulted in a significant CD86 increase $(1.41 \pm 0.15$ ratio vs unstimulated macrophages, $p$ value $<0.05)$ and CD163 decrement $(0.74 \pm 0.18, p$ value $<0.1)$. The CD86/CD163 ratio, with unstimulated macrophages set as 1 , significantly augmented to 1.9 , a clear indication of a M1 polarization (Fig. 6a). When secretome was added together with inflammatory stimuli, CD163 reduction was completely abolished with respect to unstimulated macrophages $(1.07 \pm 0.24$ ratio, $p$ value $>0.1)$ due to a $44 \pm 5 \%(p$ value $<0.01)$ increase of the M2 marker vs IFN $\gamma / \mathrm{TNF} \alpha$ cells. Eventually, when IFN $\gamma$-primed secretome was tested, CD163 levels further increased $(60 \pm 11 \%, p$ value $<0.05)$ with a significant upregulation with respect to non-primed secretome $(11 \% \pm 3 \%, p$ value $<0.05)$, meaning an almost complete prevention of the polarization of macrophages to the M1 pro-inflammatory phenotype as also indicated by the CD86/CD163 arbitrary ratio of 1.1 (Fig. 6a).
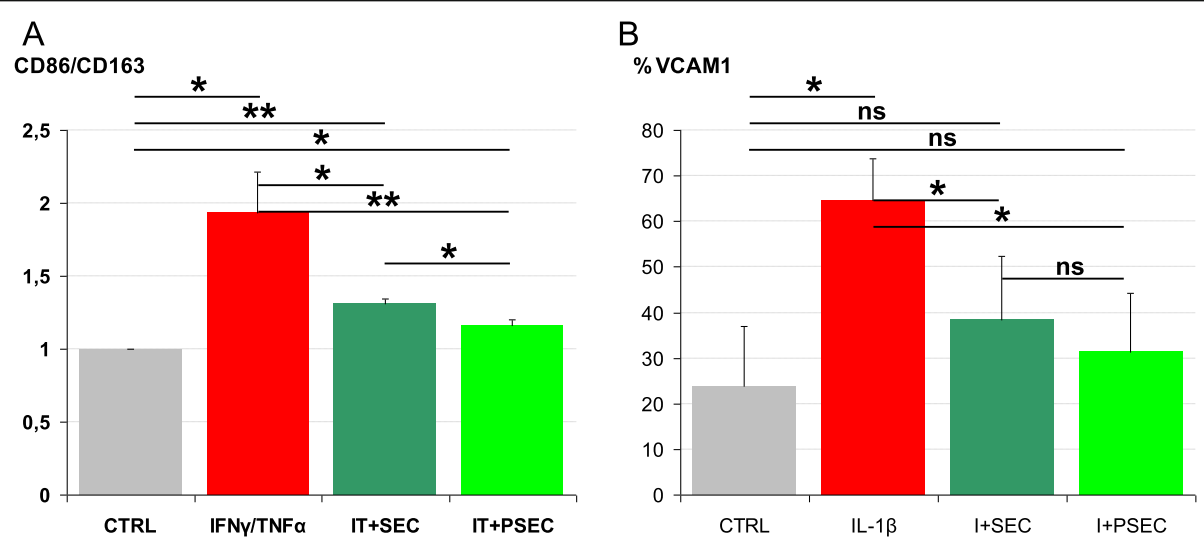

Fig. 6 Secretome effects on inflamed macrophages and chondrocytes. a Macrophages (CTRL) were treated for $24 \mathrm{~h}$ with inflammatory cytokines without (IFNY/TNFa) and with secretome (IT+SEC) or IFNy-primed secretome (IT+PSEC). Untreated cells were used as control (CTRL). CD86 (M1 phenotype) and CD163 (M2 phenotype) were detected by flow cytometry. Values on the $y$-axis are intended as ratios obtained comparing CD86 and CD163 median fluorescence intensities subtracted of their unstained control values and arbitrarily set as 1 for CTRL. Increased CD86/CD163 ratio is an indication of $\mathrm{M} 1$ phenotype polarization. $\mathbf{b}$ Chondrocytes (CTRL) were treated with inflammatory cytokine without (IL-1 $\beta$ ) and with secretome (I+SEC) or IFNy-primed secretome (I+PSEC). VCAM1 was detected by flow cytometry. Values on the $y$-axis show the percentage of VCAM1-positive cells. $N=3,{ }^{*} p<0.05,{ }^{* *} p<0.01$; ns, not significant 


\section{Validation of secretome effects and IFNY priming on inflamed chondrocytes}

Secretome activity was also monitored on inflamed chondrocytes. A chronic and low level IL-1 $\beta(25 \mathrm{pg} / \mathrm{ml})$ treatment was used accordingly to a protocol developed in our laboratory to mimic the osteoarthritis environment on synoviocytes [27]. VCAM1 positivity was tested by flow cytometry due to its responsiveness to chondrocyte inflammation and response to environmental metabolic alterations $[44,45]$. One week of IL- $1 \beta$ treatment was able to significantly ( $p$ value $<0.05)$ modulate VCAM1 expression increasing the percentage of positive cells from $24 \pm 13 \%$ to $65 \pm 9 \%$ (Fig. 6b). When the secretome was added, after 4 days, even in presence of the inflammatory stimulus, the number of VCAM1+ chondrocytes reduced to $38 \pm 14 \%$. The secretome + IL$1 \beta$ vs IL- $1 \beta$ ratio of VCAM $1+$ cells was $0.58 \pm 0.15(p$ value $<0.05)$. Finally, IFN $\gamma$-primed secretome further decreased VCAM $1+$ cells $(31 \pm 13 \%, p$ value $<0.05)$ and the ratio vs $\mathrm{IL}-1 \beta$ cells $(0.47 \pm 0.14, p$ value $<0.05)$. Of note, although not significant when comparing gross VCAM1+ percentages, the IFN $\gamma$-primed secretome vs secretome ratio resulted $0.80 \pm 0.05$ ( $p$ value $<0.05)$, suggesting a more potent anti-inflammatory activity after priming and confirming in silico data.

\section{Discussion}

In this work, both soluble factors and EV-shuttled miRNAs have been characterized in serum-free ASC secretome, and the influence of IFN $\gamma$ preconditioning evaluated. In a context of shared overall protective signals, inflammatory priming was able to tip the balance towards a more pronounced tissue regenerative and anti-inflammatory phenotype. Further, on a general perspective, identified molecules may be a useful array for future in vitro and in vivo potency assays able to define a new generation of secretome-based products and disease-driven clinical targets.

Few factors are secreted at high rates $(>100 \mathrm{ng})$ and may shuttle a message that goes beyond or drive the global scenario. Follistatin [46] is by far the most abundant (>500 ng). In an OA mouse model, follistatin reduced synovial inflammation [47] by binding the synovia-derived and macrophage activator activin A [48]. Therefore, follistatin may contribute to observed anti-inflammatory activity of secretome in OA [49]. TIMP2 (200 ng) and TIMP1 (> $30 \mathrm{ng}$ ), inhibitors of matrix metalloproteinases (MMPs), may contribute to observed prevention of cartilage degradation in both an in vivo and a phase I/II study [50,51]. The same paradigm may be also applied for other pathologies involving TIMP/MMP balance as skeletal dysplasias, coronary artery and heart disease, cancer, and brain disorders [52]. IGFBP4 (144 ng), with IGFBP6 (85 ng) and 3 (10 ng), was shown to balance the IGF-dependent induction of $\mathrm{CD} 4+\mathrm{FOXP} 3+$ Tregs given by MSCconditioned medium in arthritis [53]. The IGF/IGFBP axis may further contribute to properly regulate cartilage and bone homeostasis in OA pathogenesis, where IGF levels are increased [54]. Eventually, Serpin E1 (100 ng) prevents both the formation of plasmin [55] and the activity of MMPs [56]. Consistently, in OA-affected cartilage, Serpin E1 was upregulated and associated with disease severity, balancing matrix deposition/degradation [57]. Moreover, in macrophages, Serpin E1 controls invasion, adhesion, and again remodeling of the extracellular matrix, therefore being a regulator of the inflammatory process [58]. Notably, IFN $\gamma$ preconditioning neither significantly changed the amount of the most enriched factors nor allowed an already or newly secreted molecule to exceed the $100 \mathrm{ng}$ burden.

Rarely, single molecules and their interactions are able to explain the functional relationships when specific and focused pathways representing spatial and temporal sets of disease-dependent interactions are not scored [59]. Analyzing the data under this system view paradigm, abundant factors (>10 ng) framed "cellular" and "matrix disassembly" GO terms. This confirms the high overall potency for the secretome in those processes or diseases where active ECM remodeling is the crucial player [60]. Plasminogen [61] was found 5 times more abundant in its active form in OA cartilage, due to both an increase in plasminogen activator urokinase (UPA) and a reduction of inhibitor of plasminogen activator (Serpin E1) levels [62]. Cathepsins degrade extracellular ECM proteins [63] as those in the cartilage [64]. Overall, despite a crucial role in cartilage homeostasis, plasminogen/cathepsin $\mathrm{S}$ most studied contribution is related to angiogenesis $[65,66]$, a process timely and spatially correlated with leukocyte motility [67]. Notably, ASC secretome was demonstrated to show angiogenic potential in vivo and in vitro [68] and chemo-attraction for most of the immune cells [25]. These evidences were here supported by the presence of angiogenic molecules like interleukin6 and CCL2, in the >10-ng frame, and angiogenin and VEGF $\alpha$ in the 1- to 10-ng group [69]. Moreover, in the last group, enriched GO categories like "leukocyte" and "granulocyte chemotaxis" and, more in general, "cell migration" and "motility" have been found as highly represented. Interestingly, few factors were shared between these annotations, like CCL4/5 and CXCL1/5/8, all defining the "inflammatory response" group. Supporting this capacity, also CCL2 was highly expressed (13 ng), and in the < 1-ng molecules, "cell motility" and "migration" GO annotations were found, with CCL3/13 and CXCL16 in the "leukocyte chemotaxis" and "migrations" terms. CCL2/13 have their main function in monocyte trafficking, CCL3/4/5 in macrophage and NK cell migration, and CXCL1/5/8 in monocyte and neutrophil 
trafficking [70]. These data support the chemo-attractive capacity of MSC-conditioned medium that was demonstrated to enhance monocyte/macrophage motility and differentiation [71]. This may be further due to the presence of CSF1, shown to promote the differentiation and survival of monocytes/macrophages [72], and stimulate the anti-inflammatory M2 macrophage polarization supporting a CSF1-mediated reparative/homeostatic state [73]. Intriguingly, a MSC-based engineered cartilage suppressed in vivo inflammation through the alteration of macrophage phenotype and a M1 to M2 transition [74]. Overall, these results again support the immunomodulatory potential of MSC secretome, being aware that a selection of 200 molecules has been assayed and additional cytokine-dependent pathways may integrate the overall message.

Analysis of differentially expressed candidates between IFN $\gamma$-activated and naïve MSCs confirmed the up- or downregulation of various immunomodulatory factors, respectively. In the group of highly expressed proteins, only IGFB3 was lost whereas CXCL9/10 de novo appeared at $>10 \mathrm{ng}$ and CCL8 at $>1 \mathrm{ng}$. Scoring the significance of these induced factors, again "response to stimulus" and "chemotaxis/migration/motility" GO terms emerged, defined by CCL7/8 and CXCL9/10. Interestingly, CXCL9 and 10 are involved T cell recruitment and CCL8 (also called monocyte chemoattractant protein 2) specifically regulates Th2 response [70]. The presence of these factors is in agreement with higher capacity of IFN $\gamma$-inflamed MSCs to recruit $\mathrm{T}$ cells at their proximity and ability to reduce the symptoms of graft-versus-host disease (GVHD) in a mouse model [75], being CCL8 and CXCL9/10 upregulated in the mouse system after inflammation [76]. T cell attraction and recovery were shown to be coupled with IFNYdependent activation of indoleamine 2,3-dioxygenase (IDO) [76], as also observed in our setting. In fact, IDO has been demonstrated to inhibit the proliferation of PBMNC, particularly activated T lymphocytes, and prevent conversion of immunosuppressive Tregs in inflammatory Th1/Th17 cells [11]. Looking at the factors already identified without priming, chemokines involved in neutrophil activity (CXCL1/5/8) showed a significant reduction (still detectable but at $<1 \mathrm{ng}$ ) whereas CXCL16 overcame 1-ng burden (5-fold increase). To our knowledge, this is the first report showing an increase for CXCL16. Moreover, with respect to other published datasets dissecting inflamed MSC potency (reviewed in [23]), we observed some discrepancies. In particular, in our experimental conditions, out of reported upregulated molecules, CXCL9/10 confirmed the trend, CCL2/5 were not modulated, CXCL1/5/8/12 behaved in an opposite fashion and reduced, and inflammation related IL6 and IL23A did not change their amount, whereas increase of adhesion molecules (VCAM1 and ICAM1) corroborated the published data. These variations may be due to several factors. First, different inflammatory stimuli may induce alternative responses. As an example, many studies have demonstrated the divergent effects of MSCs priming with proinflammatory cytokines as IFN $\gamma$, TNF- $\alpha$, or IL- $1 \beta$ (reviewed in [24]). Second, MSC from distinct sources might respond differently to preconditioning with proinflammatory factors [77]. Eventually, many of the works aimed at dissecting secreted factors and cellular response are designed in view of directly utilizing MSCs as cellbased therapy. Therefore, often cytokine and chemokine modulation is studied in the presence of both FBS and the inflammatory insult. In the herein presented approach, that was realized in view of potential therapeutic application of the secretome, both serum and IFNY had to be removed before conditioned medium collection, thus allowing for a slightly different release/modulation of factors.

Together with secreted factors, MSC-derived EVs have been shown to replicate the therapeutic effects observed with the entire secretome [78] by transfer of DNA, proteins/peptides, lipids, organelles, mRNAs, and miRNAs [79]. In the view of placing EV-miRNA significance in the whole secretome capacity, some pitfalls have still to be overcome. First, there is a lack of consensus regarding miRNA signature among MSC-EVs from different sources $[9,80,81]$ or independent labs $[9,80]$. Therefore, the delivery of a list of identity marker molecules is still far to be defined. Second, the number of the delivered miRNAs per recipient cell may also impact the selection of important molecules. Recently, it was argued that in MSC-EVs, there is around 1.3 miRNA, even for the most abundant ones [82], and that, on average, 100 EVs would be needed to transfer one copy of a given abundant miRNA [40]. Since the number of incorporated MSC-EVs per cell ranges from few to hundred thousand [8,27], at least in stromal tissues, this opens the question on the real number of transferred molecules and their biological relevance. For these reasons, the most abundant EV-miRNAs may be those really shuttling a profound biological message. In this view, Baglio and colleagues showed that the 5 most enriched miRNAs accounted for around $50 \%$ of the total miRNA reads, whereas in Fang and Ferguson's datasets, the top 8 and 23 miRNAs represented $40 \%$ and $80 \%$ of the total, respectively $[9,80,81]$. Here, the first quartile of detected EV-miRNAs accounted for $>95 \%$ of the genetic fingerprint.

The effects of MSC-EVs are dependent on both the profiles of their miRNAs and the specific mRNA signature of target cells. Without these premises, herein detected miRNAs could be related to thousands of genes 
and dozens of GO categories (Additional file 4: Table 4). We therefore addressed OA as a focused condition. Notably, IPA analysis showed that a large number of miRNAs in the first quartile are connected with matrix or immune cell-related pathways and cascades (Additional file 5: Table 5). Nevertheless, a net effect for each single miRNA is barely predictable, and system view including target tissues or cell types is again mandatory. As a whole, EV-miRNas resulted to have a pronounced cartilage-protective features with a prevalence in reducing matrix/cartilage/ECM degradation and cartilage inflammation, together with a very mild detrimental effect on chondrocyte differentiation/homeostasis pathways. In this view, in a meta-analysis studying MSC treatment [83], the improvement in cartilage tissue quality and volume may be, at least in part, ascribed to the combined action of matrix-protective factors and miRNAs affecting chondrocyte homeostasis. Regarding macrophage polarization, abundant EVs have a prevalence for M2protective signals that are increased by IFN $\gamma$ preconditioning, a situation similar to what may happen when MSCs are injected in the diseased and inflamed joint cavity. In this perspective, in the synovial fluid of an OA porcine model, MSC-EVs were able to mobilize monocytes [84] that, in view of herein presented results, could polarize to an anti-inflammatory M2 phenotype. This was confirmed in an in vivo model of induced OA where amniotic fluid-derived MSC-EVs allowed macrophage M2 polarization with an almost complete restoration of cartilage, enhancing pain tolerance [85]. Thus, the combination of both M2 macrophage polarizing and cartilage protecting miRNAs and cytokines may at least in part explain the result of the Iijima meta-analysis on pain, where a significant improvement has been reported [83].

Overall, the combination of secreted factors and EVmiRNAs, and therefore the ASC secretome as a whole, in silico appeared to have both protective and antiinflammatory activities on macrophages and chondrocytes, suggesting its use as therapeutic product for joint diseases, as well as the inflammatory priming as an effective strategy to improve its efficacy. These bioinformatics results and those in vitro for chondrocytes and macrophages are in agreement with and integrate recent reports on the efficacy of MSC secretome, and its priming, for joint diseases which was shown to inhibit both chondrocyte catabolic and inflammatory markers and macrophage activation $[49,71,86,87]$. Likewise, in other disease settings, several priming approaches such as lipopolysaccharides, IL-1 $\beta$, or IFN $\gamma+\mathrm{TNF} \alpha$ were able to better induce M2 phenotype and IL-10 secretion [88-91]. Altogether, these evidences confirm both antiinflammatory ASC secretome potential and the enhancing ability of IFN $\gamma$ priming.

\section{Conclusions}

There is still a wide knowledge gap between a general definition of MSC-derived secretome efficacy and its modulation after priming to explain or even predict induced alteration of pathological pathways in the target cells when used as a medicinal product. Herein, presented results clearly showed how a deep characterization of both the clinical products and the diseased cells or tissue types is crucial to envision the therapeutic efficacy, as we observed for OA-affected cartilage and macrophages. Further studies will be needed to describe in more detail the secretome at proteic, lipidic, or nucleic acid levels in order to couple the overall fingerprint with the wide array of pathologies potentially treatable with off-the-shelf MSC cell-free products.

\section{Supplementary information}

Supplementary information accompanies this paper at https://doi.org/10. 1186/s13287-020-01677-9.

Additional file 1: Table 1. List of detected soluble factors and their molecular function in ASC/iASC secretome.

Additional file 2: Table 2. Expression values and ratios for detected soluble factors in ASC/iASC secretome.

Additional file 3: Table 3. Expression values and ratios for miRNAs in ASC/iASC EVs.

Additional file 4: Table 4. Potential BP targets based on in silico predicted miRNA-mRNA interactions.

Additional file 5: Table 5. Ingenuity Pathway Analysis on experimentally verified miRNA-mRNA interactions.

\section{Abbreviations}

MSC: Mesenchymal stromal cells; ASC: Adipose-derived MSC; BMMSC: Bone marrow-derived MSC; EV: Extracellular vesicles; OA: Osteoarthritis; GO: Gene Ontology; MMP: Matrix metalloproteinase; TIMP: Tissue inhibitor of metalloproteinase

\section{Acknowledgements}

The authors wish to thank Dr. Salvatore Criniti and Dr. Gaia Lugano for the valuable help in data generation and management. The authors also wish to thank Dr. Silvia Lopa for her sharing of expertise and Prof. Giuseppe Banfi for the useful discussions.

\section{Authors' contributions}

Conceptualization: ER and CPO. Methodology: ER, CPO, and CM. Validation: PDL and MV. Formal analysis: ER and AC. Investigation: ER and CPO. Data curation: MV. Writing —original draft preparation: ER. Writing-review and editing: LdG. Supervision: LdG. Funding acquisition: LdG. All authors read and approved the final manuscript.

Funding

This work was supported by the Italian Ministry of Health, "Ricerca Corrente."

Availability of data and materials

The datasets and raw data generated and/or analyzed during the current study are available in the OSF repository, https://osf.io/2sg9e/

Ethics approval and consent to participate

The research was performed at IRCCS Istituto Ortopedico Galeazzi under Institutional Review Board approval (San Raffaele Hospital Ethics Committee approval in date March 8, 2018, registered under number 6/int/2018). Specimens were collected after obtainment of patient informed consent 
(CI_REGAIN_adulto_v2), and following the 1964 Helsinki declaration and its later amendments or comparable ethical standards.

\section{Consent for publication}

Not applicable.

\section{Competing interests}

The authors declare that they have no competing interests.

\section{Author details}

${ }^{1}$ IRCCS Istituto Ortopedico Galeazzi, Laboratorio di Biotecnologie Applicate all'Ortopedia, Via R. Galeazzi 4, Milan 20161, Italy. ${ }^{2}$ IRCCS Istituto Ortopedico Galeazzi, Cell and Tissue Engineering Laboratory, Via R. Galeazzi 4, Milan 20161, Italy.

\section{Received: 20 December 2019 Revised: 23 March 2020} Accepted: 14 April 2020 Published online: 28 April 2020

\section{References}

1. Jossen V, van den Bos C, Eibl R, Eibl D. Manufacturing human mesenchymal stem cells at clinical scale: process and regulatory challenges. Appl Microbiol Biotechnol. 2018. https://doi.org/10.1007/s00253-018-8912-x.

2. Kabat M, Bobkov I, Kumar S, Grumet M. Trends in mesenchymal stem cell clinical trials 2004-2018: is efficacy optimal in a narrow dose range? Stem Cells Transl Med. 2020. https://doi.org/10.1002/sctm.19-0202.

3. Di Matteo B, Vandenbulcke F, Vitale ND, lacono F, Ashmore K, Marcacci M, Kon E. Minimally manipulated mesenchymal stem cells for the treatment of knee osteoarthritis: a systematic review of clinical evidence. Stem Cells Int 2019. https://doi.org/10.1155/2019/1735242

4. Kyurkchiev D, Bochev I, Ivanova-Todorova E, Mourdjeva M, Oreshkova T, Belemezova K, Kyurkchiev S. Secretion of immunoregulatory cytokines by mesenchymal stem cells. World J Stem Cells. 2014. https://doi.org/10.4252/ wjsc.v6.i5.552.

5. Eleuteri S, Fierabracci A. Insights into the secretome of mesenchymal stem cells and its potential applications. Int J Mol Sci. 2019. https://doi.org/10. 3390/ijms20184597.

6. Witwer KW, Van Balkom BWM, Bruno S, Choo A, Dominici M, Gimona M, Hill AF, De Kleijn D, Koh M, Lai RC, Mitsialis SA, Ortiz LA, Rohde E, Asada T, Toh WS, Weiss DJ, Zheng L, Giebel B, Lim SK. Defining mesenchymal stromal cell (MSC)-derived small extracellular vesicles for therapeutic applications. J Extracell Vesicles. 2019. https://doi.org/10.1080/20013078.2019.1609206.

7. Batagov AO, Kurochkin IV. Exosomes secreted by human cells transport largely mRNA fragments that are enriched in the $3^{\prime}$-untranslated regions. Biol Direct. 2013. https://doi.org/10.1186/1745-6150-8-12.

8. Ragni E, Banfi F, Barilani M, Cherubini A, Parazzi V, Larghi P, Dolo V, Bollati V, Lazzari L. Extracellular vesicle-shuttled mRNA in mesenchymal stem cell communication. Stem Cells. 2017. https://doi.org/10.1002/stem.2557.

9. Ferguson SW, Wang J, Lee CJ, Liu M, Neelamegham S, Canty JM, Nguyen J. The microRNA regulatory landscape of MSC-derived exosomes: a systems view. Sci Rep. 2018. https://doi.org/10.1038/s41598-018-19581-x.

10. Yin K, Wang S, Zhao RC. Exosomes from mesenchymal stem/stromal cells: a new therapeutic paradigm. Biomark Res. 2019. https://doi.org/10.1186/ s40364-019-0159-x.

11. Harrell CR, Fellabaum C, Jovicic N, Djonov V, Arsenijevic N, Volarevic V. Molecular mechanisms responsible for therapeutic potential of mesenchymal stem cell-derived secretome. Cells. 2019. https://doi.org/10. 3390/cells8050467.

12. Zhou BR, Xu Y, Guo SL, Xu Y, Wang Y, Zhu F, Permatasari F, Wu D, Yin ZQ Luo D. The effect of conditioned media of adipose-derived stem cells on wound healing after ablative fractional carbon dioxide laser resurfacing. Biomed Res Int. 2013. https://doi.org/10.1155/2013/519126.

13. Kordelas L, Rebmann V, Ludwig AK, Radtke S, Ruesing J, Doeppner TR, Epple M, Horn PA, Beelen DW, Giebel B. MSC-derived exosomes: a novel tool to treat therapy-refractory graft-versus-host disease. Leukemia. 2014. https:// doi.org/10.1038/leu.2014.41.

14. Fukuoka $\mathrm{H}$, Suga $\mathrm{H}$. Hair regeneration treatment using adipose-derived stem cell conditioned medium: follow-up with trichograms. Eplasty. 2015:15:e10

15. Shin H, Ryu HH, Kwon O, Park BS, Jo SJ. Clinical use of conditioned media of adipose tissue-derived stem cells in female pattern hair loss: a retrospective case series study. Int J Dermatol. 2015. https://doi.org/10.1111/ijd.12650.
16. Katagiri W, Osugi M, Kawai T, Hibi H. First-in-human study and clinical case reports of the alveolar bone regeneration with the secretome from human mesenchymal stem cells. Head Face Med. 2016. https://doi.org/10.1186/ s13005-016-0101-5.

17. Shariatzadeh M, Song J, Wilson SL. The efficacy of different sources of mesenchymal stem cells for the treatment of knee osteoarthritis. Cell Tissue Res. 2019. https://doi.org/10.1007/s00441-019-03086-8.

18. Hemeda H, Jakob M, Ludwig AK, Giebel B, Lang S, Brandau S. Interferongamma and tumor necrosis factor-alpha differentially affect cytokine expression and migration properties of mesenchymal stem cells. Stem Cells Dev. 2010. https://doi.org/10.1089/scd.2009.0365.

19. Elahi KC, Klein G, Avci-Adali M, Sievert KD, MacNeil S, Aicher WK. Human mesenchymal stromal cells from different sources diverge in their expression of cell surface proteins and display distinct differentiation patterns. Stem Cells Int. 2016. https://doi.org/10.1155/2016/5646384.

20. Waterman RS, Tomchuck SL, Henkle SL, Betancourt AM. A new mesenchymal stem cell (MSC) paradigm: polarization into a proinflammatory MSC1 or an immunosuppressive MSC2 phenotype. PLoS One. 2010. https://doi.org/10.1371/journal.pone.0010088.

21. Guan Q, Ezzati P, Spicer V, Krokhin O, Wall D, Wilkins JA. Interferon $Y$ induced compositional changes in human bone marrow derived mesenchymal stem/stromal cells. Clin Proteomics. 2017. https://doi.org/10. 1186/s12014-017-9161-1.

22. de Witte SF, Franquesa M, Baan CC, Hoogduijn MJ. Toward development of iMesenchymal stem cells for immunomodulatory therapy. Front Immunol. 2016. https://doi.org/10.3389/fimmu.2015.00648.

23. Barrachina L, Remacha AR, Romero A, Vitoria A, Albareda J, Prades M, Roca M, Zaragoza P, Vázquez FJ, Rodellar C. Assessment of effectiveness and safety of repeat administration of proinflammatory primed allogeneic mesenchymal stem cells in an equine model of chemically induced osteoarthritis. BMC Vet Res. 2018. https://doi.org/10.1186/s12917-018-1556-3.

24. Duijvestein M, Wildenberg ME, Welling MM, Hennink S, Molendijk I, van Zuylen VL, Bosse T, Vos AC, de Jonge-Muller ES, Roelofs $H$, van der Weerd L, Verspaget HW, Fibbe WE, te Velde AA, van den Brink GR, Hommes DW. Pretreatment with interferon- $\gamma$ enhances the therapeutic activity of mesenchymal stromal cells in animal models of colitis. Stem Cells. 2011. https://doi.org/10.1002/stem.698.

25. Ferreira JR, Teixeira GQ, Santos SG, Barbosa MA, Almeida-Porada G, Gonçalves RM. Mesenchymal stromal cell secretome: influencing therapeutic potential by cellular pre-conditioning. Front Immunol. 2018. https://doi.org/10.3389/fimmu.2018.02837.

26. Noronha NC, Mizukami A, Caliári-Oliveira C, Cominal JG, Rocha JLM, Covas DT, Swiech K, Malmegrim KCR. Priming approaches to improve the efficacy of mesenchymal stromal cell-based therapies. Stem Cell Res Ther. 2019. https://doi.org/10.1186/s13287-019-1224-y.

27. Ragni E, Perucca Orfei C, De Luca P, Lugano G, Viganò M, Colombini A, Valli F, Zacchetti D, Bollati V, de Girolamo L. Interaction with hyaluronan matrix and miRNA cargo as contributors for in vitro potential of mesenchymal stem cellderived extracellular vesicles in a model of human osteoarthritic synoviocytes. Stem Cell Res Ther. 2019. https://doi.org/10.1186/s13287-019-1215-z.

28. Montemurro T, Viganò $M$, Ragni E, Barilani M, Parazzi $V$, Boldrin $V$, Lavazza C, Montelatici E, Banfi F, Lauri E, Giovanelli S, Baccarin M, Guerneri S, Giordano R, Lazzari L. Angiogenic and anti-inflammatory properties of mesenchymal stem cells from cord blood: soluble factors and extracellular vesicles for cell regeneration. Eur J Cell Biol. 2016. https://doi.org/10.1016/j.ejcb.2016.04.003.

29. Ragni E, Coluccio A, Rolli E, Rodriguez-Peña JM, Colasante G, Arroyo J, Neiman AM, Popolo L. GAS2 and GAS4, a pair of developmentally regulated genes required for spore wall assembly in Saccharomyces cerevisiae. Eukaryot Cell. 2007. https://doi.org/10.1128/EC.00321-06.

30. Pergoli L, Cantone L, Favero C, Angelici L, lodice S, Pinatel E, Hoxha M, Dioni L, Letizia M, Albetti B, Tarantini L, Rota F, Bertazzi PA, Tirelli AS, Dolo V Cattaneo A, Vigna L, Battaglia C, Carugno M, Bonzini M, Pesatori AC, Bollati $\checkmark$. Extracellular vesicle-packaged miRNA release after short-term exposure to particulate matter is associated with increased coagulation. Part Fibre Toxicol. 2017. https://doi.org/10.1186/s12989-017-0214-4.

31. D'haene B, Mestdagh P, Hellemans J, Vandesompele J. miRNA expression profiling: from reference genes to global mean normalization. Methods Mol Biol. 2012. https://doi.org/10.1007/978-1-61779-427-8_18.

32. Boyle El, Weng S, Gollub J, Jin H, Botstein D, Cherry JM, Sherlock G. GO: TermFinder--open source software for accessing Gene Ontology 
information and finding significantly enriched Gene Ontology terms associated with a list of genes. Bioinformatics. 2004. https://doi.org/10.1093/ bioinformatics/bth456.

33. Mi H, Huang $X$, Muruganujan A, Tang $H$, Mills C, Kang D, Thomas PD. PANTHER version 11: expanded annotation data from Gene Ontology and Reactome pathways, and data analysis tool enhancements. Nucleic Acids Res. 2017. https://doi.org/10.1093/nar/gkw1138.

34. Vlachos IS, Zagganas K, Paraskevopoulou MD, Georgakilas G, Karagkouni D, Vergoulis T, Dalamagas T, Hatzigeorgiou AG. DIANA-miRPath v3.0: deciphering microRNA function with experimental support. Nucleic Acids Res. 2015. https://doi.org/10.1093/nar/gkv403.

35. Metsalu T, Vilo J. ClustVis: a web tool for visualizing clustering of multivariate data using principal component analysis and heatmap. Nucleic Acids Res. 2015. https://doi.org/10.1093/nar/gkv468.

36. Lopa S, Leijs MJ, Moretti M, Lubberts E, van Osch GJ, Bastiaansen-Jenniskens YM. Arthritic and non-arthritic synovial fluids modulate IL10 and IL1RA gene expression in differentially activated primary human monocytes. Osteoarthr Cartil. 2015. https://doi.org/10.1016/j.joca.2015.06.003.

37. Spiller KL, Wrona EA, Romero-Torres S, Pallotta I, Graney PL, Witherel CE, Panicker LM, Feldman RA, Urbanska AM, Santambrogio L, Vunjak-Novakovic $G$, Freytes DO. Differential gene expression in human, murine, and cell linederived macrophages upon polarization. Exp Cell Res. 2016. https://doi.org/ 10.1016/j.yexcr.2015.10.017.

38. De Luca P, Kouroupis D, Viganò M, Perucca-Orfei C, Kaplan L, Zagra L, de Girolamo L, Correa D, Colombini A. Human diseased articular cartilage contains a mesenchymal stem cell-like population of chondroprogenitors with strong immunomodulatory responses. J Clin Med. 2019. https://doi. org/10.3390/jcm8040423.

39. Toh WS, Lai RC, Hui JHP, Lim SK. MSC exosome as a cell-free MSC therapy for cartilage regeneration: implications for osteoarthritis treatment. Semin Cell Dev Biol. 2017. https://doi.org/10.1016/j.semcdb.2016.11.008.

40. Chevillet JR, Kang Q, Ruf IK, Briggs HA, Vojtech LN, Hughes SM, Cheng HH, Arroyo JD, Meredith EK, Gallichotte EN, Pogosova-Agadjanyan EL, Morrissey C, Stirewalt DL, Hladik F, Yu EY, Higano CS, Tewari M. Quantitative and stoichiometric analysis of the microRNA content of exosomes. Proc Natl Acad Sci U S A. 2014. https://doi.org/10.1073/pnas.1408301111.

41. Cong $L$, Zhu $Y, T u G$. A bioinformatic analysis of microRNAs role in osteoarthritis. Osteoarthr Cartil. 2017. https://doi.org/10.1016/j.joca.2017.03. 012.

42. Xu SJ, Hu HT, Li HL, Chang S. The role of miRNAs in immune cell development, immune cell activation, and tumor immunity: with a focus on macrophages and natural killer cells. Cells. 2019. https://doi.org/10.3390/ cells8101140.

43. Liu B, Zhang M, Zhao J, Zheng M, Yang H. Imbalance of M1/M2 macrophages is linked to severity level of knee osteoarthritis. Exp Ther Med. 2018;1. https://doi.org/10.3892/etm.2018.6852.

44. Conde J, Scotece M, López V, Gómez R, Lago F, Pino J, Gómez-Reino JJ, Gualillo O. Adiponectin and leptin induce VCAM-1 expression in human and murine chondrocytes. PLoS One. 2012. https://doi.org/10.1371/journal.pone. 0052533.

45. Žigon-Branc S, Barlič A, Knežević M, Jeras M, Vunjak-Novakovic G. Testing the potency of anti-TNF-á and anti-IL-1â drugs using spheroid cultures of human osteoarthritic chondrocytes and donor-matched chondrogenically differentiated mesenchymal stem cells. Biotechnol Prog. 2018. https://doi. org/10.1002/btpr.2629.

46. Lee SJ, Lee YS, Zimmers TA, Soleimani A, Matzuk MM, Tsuchida K, Cohn RD, Barton ER. Regulation of muscle mass by follistatin and activins. Mol Endocrinol. 2010. https://doi.org/10.1210/me.2010-0127.

47. Yamada J, Tsuji K, Miyatake K, Matsukura Y, Abula K, Inoue M, Sekiya I, Muneta T. Follistatin alleviates synovitis and articular cartilage degeneration induced by carrageenan. Int J Inflam. 2014. https://doi.org/10.1155/2014/ 959271

48. Nüsing RM, Barsig J. Induction of prostanoid, nitric oxide, and cytokine formation in rat bone marrow derived macrophages by activin $\mathrm{A} . \mathrm{Br} J$ Pharmacol. 1999. https://doi.org/10.1038/sj.bjp.0702626.

49. Mancuso P, Raman S, Glynn A, Barry F, Murphy JM. Mesenchymal stem cell therapy for osteoarthritis: the critical role of the cell secretome. Front Bioeng Biotechnol. 2019. https://doi.org/10.3389/fbioe.2019.00009.

50. Saulnier N, Viguier E, Perrier-Groult E, Chenu C, Pillet E, Roger T, Maddens S, Boulocher C. Intra-articular administration of xenogeneic neonatal Mesenchymal stromal cells early after meniscal injury down-regulates metalloproteinase gene expression in synovium and prevents cartilage degradation in a rabbit model of osteoarthritis. Osteoarthr Cartil. 2015. https://doi.org/10.1016/j.joca.2014.09.007.

51. Matas J, Orrego M, Amenabar D, Infante C, Tapia-Limonchi R, Cadiz MI, Alcayaga-Miranda F, González PL, Muse E, Khoury M, Figueroa FE, Espinoza F. Umbilical cord-derived mesenchymal stromal cells (MSCs) for knee osteoarthritis: repeated MSC dosing is superior to a single MSC dose and to hyaluronic acid in a controlled randomized phase I/II trial. Stem Cells Transl Med. 2019. https://doi.org/10.1002/sctm.18-0053.

52. Malemud CJ. Matrix metalloproteinases (MMPs) in health and disease: an overview. Front Biosci. 2006. https://doi.org/10.2741/1915.

53. Miyagawa I, Nakayamada S, Nakano K, Yamagata K, Sakata K, Yamaoka K, Tanaka $Y$. Induction of regulatory $T$ cells and its regulation with insulin-like growth factor/insulin-like growth factor binding protein-4 by human mesenchymal stem cells. J Immunol. 2017. https://doi.org/10.4049/ jimmunol.1600230.

54. Martel-Pelletier J, Di Battista JA, Lajeunesse D, Pelletier JP. IGF/IGFBP axis in cartilage and bone in osteoarthritis pathogenesis. Inflamm Res. 1998. https://doi.org/10.1007/s000110050288.

55. Carter JC, Church FC. Obesity and breast cancer: the roles of peroxisome proliferator-activated receptor- $y$ and plasminogen activator inhibitor-1. PPAR Res. 2009. https://doi.org/10.1155/2009/345320.

56. Lee E, Vaughan DE, Parikh SH, Grodzinsky AJ, Libby P, Lark MW, Lee RT. Regulation of matrix metalloproteinases and plasminogen activator inhibitor-1 synthesis by plasminogen in cultured human vascular smooth muscle cells. Circ Res. 1996. https://doi.org/10.1161/01.res.78.1.44.

57. Ramos YF, den Hollander W, Bovée JV, Bomer N, van der Breggen R, Lakenberg N, Keurentjes JC, Goeman JJ, Slagboom PE, Nelissen RG, Bos SD, Meulenbelt I. Genes involved in the osteoarthritis process identified through genome wide expression analysis in articular cartilage; the RAAK study. PLoS One. 2014. https://doi.org/10.1371/journal.pone.0103056.

58. Fleetwood AJ, Achuthan A, Schultz H, Nansen A, Almholt K, Usher P, Hamilton JA. Urokinase plasminogen activator is a central regulator of macrophage three-dimensional invasion, matrix degradation, and adhesion. J Immunol. 2014. https://doi.org/10.4049/jimmunol.1302864.

59. Stoney R, Robertson DL, Nenadic G, Schwartz JM. Mapping biological process relationships and disease perturbations within a pathway network. NPJ Syst Biol Appl. 2018. https://doi.org/10.1038/s41540-0180055-2.

60. Bonnans C, Chou J, Werb Z. Remodelling the extracellular matrix in development and disease. Nat Rev Mol Cell Biol. 2014. https://doi.org/10. 1038/nrm3904.

61. Smith HW, Marshall CJ. Regulation of cell signalling by uPAR. Nat Rev Mol Cell Biol. 2010. https://doi.org/10.1038/nrm2821.

62. Martel-Pelletier J, Faure MP, McCollum R, Mineau F, Cloutier JM, Pelletier JP. Plasmin, plasminogen activators and inhibitor in human osteoarthritic cartilage. J Rheumatol. 1991;18:1863-71.

63. Mohamed MM, Sloane BF. Cysteine cathepsins: multifunctional enzymes in cancer. Nat Rev Cancer. 2006. https://doi.org/10.1038/nrm2821, https://doi. org/10.1038/nrc1949.

64. Hou WS, Li W, Keyszer G, Weber E, Levy R, Klein MJ, Gravallese EM, Goldring SR, Brömme D. Comparison of cathepsins $K$ and $S$ expression within the rheumatoid and osteoarthritic synovium. Arthritis Rheum. 2002. https://doi. org/10.1002/art.10114.

65. Oh CW, Hoover-Plow J, Plow EF. The role of plasminogen in angiogenesis in vivo. J Thromb Haemost. 2003. https://doi.org/10.1046/j.1538-7836.2003. 00182.x.

66. Shi GP, Sukhova GK, Kuzuya M, Ye Q, Du J, Zhang Y, Pan JH, Lu ML, Cheng XW, Iguchi A, Perrey S, Lee AM, Chapman HA, Libby P. Deficiency of the cysteine protease cathepsin S impairs microvessel growth. Circ Res. 2003. https://doi.org/10.1161/01.RES.0000060485.20318.96.

67. Corliss BA, Azimi MS, Munson JM, Peirce SM, Murfee WL. Macrophages: an inflammatory link between angiogenesis and lymphangiogenesis. Microcirculation. 2016. https://doi.org/10.1111/micc.12259.

68. Lu H, Wang F, Mei H, Wang S, Cheng L. Human adipose mesenchymal stem cells show more efficient angiogenesis promotion on endothelial colonyforming cells than umbilical cord and endometrium. Stem Cells Int. 2018. https://doi.org/10.1155/2018/7537589.

69. Tao H, Han Z, Han ZC, Li Z. Proangiogenic features of mesenchymal stem cells and their therapeutic applications. Stem Cells Int. 2016. https://doi.org/ $10.1155 / 2016 / 1314709$ 
70. Sokol CL, Luster AD. The chemokine system in innate immunity. Cold Spring Harb Perspect Biol. 2015. https://doi.org/10.1101/cshperspect. a016303.

71. Kehl D, Generali M, Mallone A, Heller M, Uldry AC, Cheng P, Gantenbein B, Hoerstrup SP, Weber B. Proteomic analysis of human mesenchymal stromal cell secretomes: a systematic comparison of the angiogenic potential. NPJ Regen Med. 2019. https://doi.org/10.1038/s41536-019-0070-y.

72. Sordet O, Rébé C, Plenchette S, Zermati Y, Hermine O, Vainchenker W, Garrido C, Solary E, Dubrez-Daloz L. Specific involvement of caspases in the differentiation of monocytes into macrophages. Blood. 2002. https://doi.org/ 10.1182/blood-2002-06-1778.

73. Hamilton JA. Colony-stimulating factors in inflammation and autoimmunity. Nat Rev Immunol. 2008. https://doi.org/10.1038/nri2356.

74. Ding J, Chen B, Lv T, Liu X, Fu X, Wang Q, Yan L, Kang N, Cao Y, Xiao R. Bone marrow mesenchymal stem cell-based engineered cartilage ameliorates polyglycolic acid/polylactic acid scaffold-induced inflammation through M2 polarization of macrophages in a pig model. Stem Cells Trans Med. 2016. https://doi.org/10.5966/sctm.2015-0263.

75. Ren G, Zhang L, Zhao X, Xu G, Zhang Y, Roberts Al, Zhao RC, Shi Y. Mesenchymal stem cell-mediated immunosuppression occurs via concerted action of chemokines and nitric oxide. Cell Stem Cell. 2008. https://doi.org/ 10.1016/j.stem.2007.11.014.

76. Kim DS, Jang IK, Lee MW, Ko YJ, Lee DH, Lee JW, Sung KW, Koo HH, Yoo KH. Enhanced immunosuppressive properties of human mesenchymal stem cells primed by interferon- $\gamma$. EBioMedicine. 2018. https://doi.org/10.1016/j. ebiom.2018.01.002

77. Najar M, Raicevic G, Fayyad-Kazan H, De Bruyn C, Bron D, Toungouz M, Lagneaux L. Immune-related antigens, surface molecules and regulatory factors in human-derived mesenchymal stromal cells: the expression and impact of inflammatory priming. Stem Cell Rev Rep. 2012. https://doi.org/10. 1007/s12015-012-9408-1.

78. Silva AM, Teixeira JH, Almeida MI, Gonçalves RM, Barbosa MA, Santos SG. Extracellular vesicles: immunomodulatory messengers in the context of tissue repair/regeneration. Eur J Pharm Sci. 2017. https://doi.org/10.1016/j. ejps.2016.09.017.

79. Qiu G, Zheng G, Ge M, Wang J, Huang R, Shu Q, Xu J. Mesenchymal stem cell-derived extracellular vesicles affect disease outcomes via transfer of microRNAs. Stem Cell Res Ther. 2018. https://doi.org/10.1186/s13287-0181069-9.

80. Baglio SR, Rooijers K, Koppers-Lalic D, Verweij FJ, Pérez Lanzón M, Zini N, Naaijkens B, Perut F, Niessen HW, Baldini N, Pegtel DM. Human bone marrow- and adipose-mesenchymal stem cells secrete exosomes enriched in distinctive miRNA and tRNA species. Stem Cell Res Ther. 2015. https://doi. org/10.1186/s13287-015-0116-Z

81. Fang S, Xu C, Zhang Y, Xue C, Yang C, Bi H, Qian X, Wu M, Ji K, Zhao Y, Wang $Y$, Liu H, Xing X. Umbilical cord-derived mesenchymal stem cellderived exosomal microRNAs suppress myofibroblast differentiation by inhibiting the transforming growth factor-B/SMAD2 pathway during wound healing. Stem Cells Transl Med. 2016. https://doi.org/10.5966/sctm.20150367.

82. Toh WS, Lai RC, Zhang B, Lim SK. MSC exosome works through a proteinbased mechanism of action. Biochem Soc Trans. 2018. https://doi.org/10. 1042/BST20180079.

83. lijima H, Isho T, Kuroki H, Takahashi M, Aoyama T. Effectiveness of mesenchymal stem cells for treating patients with knee osteoarthritis: a meta-analysis toward the establishment of effective regenerative rehabilitation. NPJ Regen Med. 2018. https://doi.org/10.1038/s41536-0180041-8.

84. Casado JG, Blázquez R, Vela FJ, Álvarez V, Tarazona R, Sánchez-Margallo FM. Mesenchymal stem cell-derived exosomes: immunomodulatory evaluation in an antigen-induced synovitis porcine model. Front Vet Sci. 2017. https:// doi.org/10.3389/fvets.2017.00039.

85. Zavatti M, Beretti F, Casciaro F, Bertucci E, Maraldi T. Comparison of the therapeutic effect of amniotic fluid stem cells and their exosomes on monoiodoacetate-induced animal model of osteoarthritis. Biofactors. 2019 https://doi.org/10.1002/biof.1576.

86. Cosenza S, Ruiz M, Toupet K, Jorgensen C, Noël D. Mesenchymal stem cells derived exosomes and microparticles protect cartilage and bone from degradation in osteoarthritis. Sci Rep. 2017. https://doi.org/10.1038/s41598017-15376-8.
87. D'Arrigo D, Roffi A, Cucchiarini M, Moretti M, Candrian C, Filardo G. Secretome and extracellular vesicles as new biological therapies for knee osteoarthritis: a systematic review. J Clin Med. 2019. https://doi.org/10.3390/ jcm8111867.

88. Domenis R, Cifù A, Quaglia S, Pistis C, Moretti M, Vicario A, Parodi PC, Fabris M, Niazi KR, Soon-Shiong P, Curcio F. Pro inflammatory stimuli enhance the immunosuppressive functions of adipose mesenchymal stem cells-derived exosomes. Sci Rep. 2018. https://doi.org/10.1038/s41598-018-31707-9.

89. Song Y, Dou H, Li X, Zhao X, Li Y, Liu D, Ji J, Liu F, Ding L, Ni Y, Hou Y. Exosomal miR-146a contributes to the enhanced therapeutic efficacy of interleukin-1 $\beta$-primed mesenchymal stem cells against sepsis. Stem Cells. 2017. https://doi.org/10.1002/stem.2564. Epub 2017 Feb 5.

90. Ti D, Hao H, Tong C, Liu J, Dong L, Zheng J, Zhao Y, Liu H, Fu X, Han W. LPS-preconditioned mesenchymal stromal cells modify macrophage polarization for resolution of chronic inflammation via exosome-shuttled let7b. J Transl Med. 2015. https://doi.org/10.1186/s12967-015-0642-6.

91. Xu R, Zhang F, Chai R, Zhou W, Hu M, Liu B, Chen X, Liu M, Xu Q, Liu N, Liu $\mathrm{S}$. Exosomes derived from pro-inflammatory bone marrow-derived mesenchymal stem cells reduce inflammation and myocardial injury via mediating macrophage polarization. J Cell Mol Med. 2019. https://doi.org/ 10.1111/jcmm.14635.

\section{Publisher's Note}

Springer Nature remains neutral with regard to jurisdictional claims in published maps and institutional affiliations.
Ready to submit your research? Choose BMC and benefit from:

- fast, convenient online submission

- thorough peer review by experienced researchers in your field

- rapid publication on acceptance

- support for research data, including large and complex data types

- gold Open Access which fosters wider collaboration and increased citations

- maximum visibility for your research: over $100 \mathrm{M}$ website views per year

At $\mathrm{BMC}$, research is always in progress.

Learn more biomedcentral.com/submissions 